\title{
ESTADO ACTUAL DE NUESTROS CONOCIMIENTOS SOBRE LA ENFERMEDAD DE CHAGAS EN LA REPUBLICA MEXICANA
}

\author{
Jorge Tay*, Paz Ma. Salazar S. *, Martha Irene Bucio * \\ Renato Zarate * e Lauren Zarate**
}

\begin{abstract}
Se presentan los datos obtenidos de la revisión minuciosa en relación a enfermedad de Cha. gas de la literatura médica de la República Mexicana y extranjera desde el año de 1939 en que por primeira vez se reporta a Trypanosoma cruzi en México, hasta el año de 1976.

Mediante mapas, tablas y cuadros se señalan las localidades en donde se han encontrado ca. sos humanos, reservorios no humanos y transmisores. Se hacen comentarios acerca de los resultados obtenidos y se señala la importancia de incrementar los estudios sobre enfermedades de Chagas en nuestro pais.
\end{abstract}

\section{INTRODUCCION}

Desde la última revisión sobre enfermedad de Chagas publicada en México por Biagi y cols. en $1964^{11}$ hasta la fecha, aunque son pocos los estudios realizados sobre el tema, ya se han interessado un número mayor de investigadores $y$ han aparecido en la Literatura Médica Nacional, reportes de hallazgos sobre la tripanosomiasis antes mencionada ${ }^{1,28}$.

Como esta línea de trabajo la hemos venido realizando ininterrumpidamente durante todo este tiempo $y$ hemos contribuído en parte al conocimiento de dicha enfermedad en nuestro país $8,9,10,13,25,36,62,73,77$, creemos conveniente reunir en esta publicación lo que se ha logrado hasta el momento en relación con la enfermedad de Chagas.

\section{MATERIAL Y METODOS}

En esta publicación se vierten las informaciones obtenidas mediante la consulta de revistas de información médica y científica de la República Mexicana y del extranjero, así como de las pláticas sostenidas con otros investigadores del país y las experiencia de los autores. Todo el material obtenido se presenta de la manera siguiente: casos humanos, reservorios, transmisores, estudios realizados con cepas de Trypanosoma cruzi aislado: de la República Mexicana y otros estudios. Todo lo anterior, ilustrado mediante tablas, cuadros y mapas

\section{RESULTADOS Y DISCUSION}

\section{CASOS HUMANOS}

Hasta el año de 1961, sólo se habían reportado 6 casos humanos comprobados parasitológicamente ${ }^{8,33,38,41}$, en los últimos 16 años se han reportado 133 casos más, lo que hace un total de 139 (Tabla No. 1).

Por to que podemos ver en la Tabla y el Mapa número 1 , en los que se anotan las localidades en que se han encontrado casos humanos, la gran mayoría de ellos se localizan en regiones que se encuentran dentro de la

* Departamento de Ecologia Humana, Facultad de Medicina, Universidad Nacional Autónoma de Mexico. 
TABLA No. 1

RELACION DE CASOS HUMANOS COMPROBADOS

DE TRIPANOSOMIASIS AMERICANA, REGISTRADO EN MEXICO

(1940-1977)

\begin{tabular}{|c|c|c|c|}
\hline $\begin{array}{c}\text { ANO } \\
\text { REPORTADO }\end{array}$ & $\begin{array}{c}\text { No. } \\
\text { CASOS }\end{array}$ & MUNICIPIO Y ESTADO & INVESTIGADOR(ES) \\
\hline 1940 & 2 & Teojomulco, Oaxaca & Mazzotti (33) \\
\hline 1947 & 2 & Mérida, Yucatán & Palomo (41) \\
\hline 1958 & 1 & Tutuapa, Edo. de México & Biagi y col. (8) \\
\hline 1959 & 1 & Guaymas, Sonora & Palencia y Montaño (38) \\
\hline 1961 & 1 & Atoyac, Guerrero & Rodriguez, J. (54) \\
\hline 1961 & 1 & Mixteca Baja, Oaxaca & Tay y col. (63) \\
\hline 1964 & 1 & Tetitlán, Guerrero & Biagi, Tay y cols. (11) \\
\hline 1964 & 4 & Compostela, Nayarit & Pérez Reyes** \\
\hline 1965 & 1 & Tierra Blanca, Veracruz & Fernàndez (22) \\
\hline 1965 & 1 & Limón, Oaxaca & Arce y Biagi (12) \\
\hline 1965 & 1 & Tutepec, Oaxaca & Arce y Biagi (12) \\
\hline 1966 & 1 & Tuxpan, Michoacán & Tay y Navarrete (64) \\
\hline 1967 & 5 & $\begin{array}{l}\text { Tepechitlán y Jalpa, Zacatecas, } \\
\text { Chimatitlán, Sta. Ma. de Los Angeles, } \\
\text { Jalisco }\end{array}$ & Cuartero y cols. (15) \\
\hline 1970 & 1 & Acatlán de Juárez, Jalisco & Velasco y cols. (79) \\
\hline 1971 & 1 & Chila, Oaxaca & Goldsmith** \\
\hline 1972 & 1 & Tepephitlán, Zacatecas & Martínez Maranón (26) \\
\hline 1972 & 1 & Jojutla, Morelos & González, A (21) \\
\hline 1973 & 1 & Humucma, Yacatán & Zavala y cols. (80) \\
\hline 1974 & 3 & A totonilco y Acatlán de Juárez, Jalisco & Velasco y Tay (77) \\
\hline 1975 & 6 & Muna I tzincab, Yucatán & Quintal y cols. (53) \\
\hline 1976 & 74 & Varios (Ref. No. 33) & C.N.E.P. (75) \\
\hline 1976 & 8 & León Brindis, Palenque & Ortega y cols. $\{36\}$ \\
\hline 1976 & 3 & Agua Azul, Chilon, Chiapas & Ortega y cols. $(36)$ \\
\hline 1977 & 18 & Yacatán & Zavala y cols.** \\
\hline
\end{tabular}

TOTAL

139

* No publicado

** Comunicación personal.

vertiente del Océano Pacífico, principalmente desde el estado de Zacatecas, hacia el sur del País; solamente en el estado de Chiapas se han reportado 42 casos humanos 36,75 ; en Jalisco24 $4^{15,75,77,79^{*}}$; en Oaxaca $10^{26,75}$, etc. Es importante señalar que la gran mayoria de los casos humanos diagnosticados, no tienen estudio clínico, o si lo tienen es superficial $y$ incompleto, por lo que no se les ha pedido determinar claramente si sufren de infeccion asintomática o si realmente fueron personas con enfermedad manifiesta, salvo en los casos que se demostró, además de la infección, miocarditis chagásica y cuadro clínico compatible con la enfermedad de Chagas.

Existen reportes de otros casos humanos que se han diagnosticado mediante reacciones serológicas o por otros medios y los cuales se reunen en la Tabla No. $2^{12,19,49,51,63,67,68}$. 
MAPA No. I

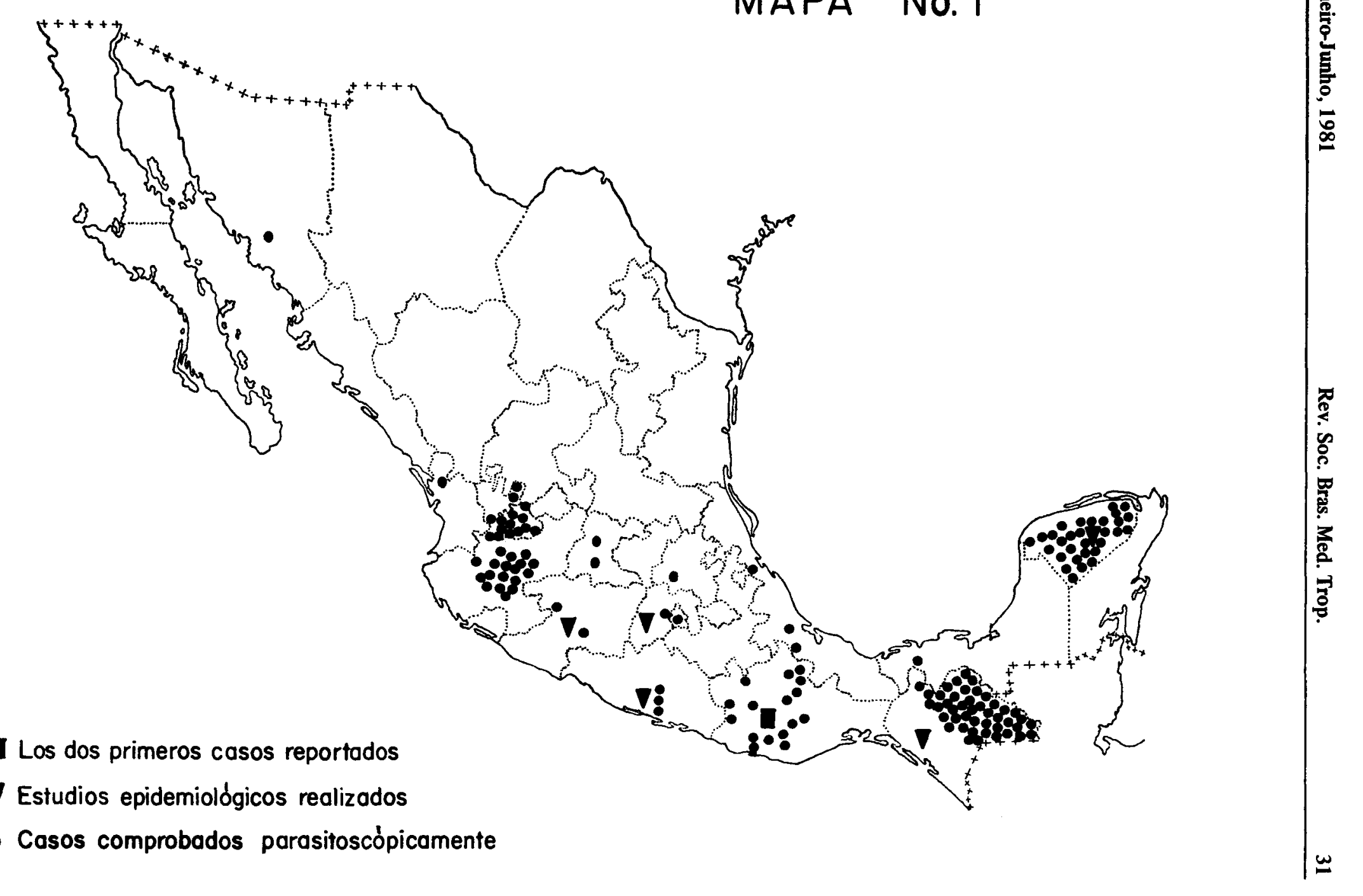


TABLA No. 2

RELACION DE CASOS HUMANOS DE TRIPANOSOMIASIS AMERICANA, DIAGNOSTICADOS POR REACCIONES SEROLOGICAS, REGISTRADOS EM MEXICO (1940-1976)

\begin{tabular}{ccccll}
\hline $\begin{array}{c}\text { Año } \\
\text { Reportado }\end{array}$ & $\begin{array}{c}\text { No Sueros } \\
\text { Estudiados }\end{array}$ & $\begin{array}{c}\text { No } \\
\text { Casos }\end{array}$ & $\%$ & Estado & Investigador \\
\hline 1947 & - & 4 & - & Guerrero & Perrin y cols. (51) \\
1949 & 200 & 18 & 8.5 & Guerrero & Biagi y cols. (49) \\
1965 & - & 2 & $-\overline{2}$ & Oaxaca & Biagi y Arce Gómez (12) \\
1967 & 165 & 12 & 7.2 & Michoacán & Tay y cols. (67) \\
1968 & 75 & 10 & 13 & Zacatecas & Tay y cols. (68) \\
1971 & 161 & 47 & 29 & Oaxaca & Goldsmith y cols. (19) \\
\hline
\end{tabular}

SIN CONFIRMACION PARASITOSCOPICA NI SEROLOGICA

POR ANTECEDENTES Y MIOCARDITIS CONFIRMADA EN LA AUTOPSIA

\begin{tabular}{ccll}
\hline $\begin{array}{c}\text { Año } \\
\text { Reportado }\end{array}$ & $\begin{array}{c}\text { No } \\
\text { Casos }\end{array}$ & Estado & Investigador \\
\hline 1961 & $\mathbf{6}$ & Oaxaca & Tay v cols. (63) \\
1968 & 2 & Zacatecas & Tay cols. (68) \\
\hline
\end{tabular}

\section{RESERVORIOS}

Los estudios realizados sobre los reservorios de $T$. cruzi en nuestro País, son tan reducidos como podemos observar en el Mapa No. 6 y en las Tablas Nos. 3 y 4 , en los que vemos que se han colectado sólo seis vertebrados mamíferos en los que se han efectuado estudios para demostrar su infección por T. cruzi. En 1947. Dias y cols., reportaron el primer reservorio que fué Didelphis marsupialis (tlacuache) ${ }^{16,51}$.

Fué en 1949 cuando Mazzotti y Dias, informaron que Dasypus mexicanus (armadillo) y Canis familiaris (perro) - habían sido encontrados infectados por Trypanosoma cruzi en condiciones naturales ${ }^{34}$. En este mismo año, Beltrán, E. reportó otro reservorio que es Rattus norvegicus (rata) ${ }^{6}$. En 1970, Velasco reporta también a Canis familiaris ${ }^{78}$.

Aunque en México no ha sido reportado Sus domesticus (cerdo), infectado por T. cruzi, Mazzotti y Brumpt, en 1939, señalan haberlo logrado en forma experimental, sin embargo, en Brasil, Pinto (1942) ${ }^{52}$, menciona que este animal se encuentra infectado en la naturaleza. Tay $y$ cols. hacen observaciones sobre hallazgos de triatomas infectados por $T$. cruzi en madrigueras de mamíferos.

En un estudio que se realizó en el estado de Jalisco (Tabla No. 4)*, además de Rattus norvegicus, ya reportado, se encontró Mus musculus y Scirus vulgaris como reservorios, sin embargo, a pesar de haber sido reportado previamente Canis familiaris como reservorio, en nuestro estudio, el resultado en este animal fué negativo; en la misma forma, el trabajo de Ortega y cols. en Chiapas, donde 18 ratones (Mus musculus) fueron negativos. Como sabemos, hay una amplia dispersión en el territorio nacional de estas especies de vertebrados, por lo cual, pensamos que se deben hacer más estudios sobre este renglón, que consideramos de suma importancia y sobre el cual casi no se tienen datos.

\section{TRANSMISORES.}

En el conocimiento de los transmisores de Trypanosoma cruzi, es quizá el aspecto sobre el que más se ha contribuído, ya que desde los 
TABLA No. 3

INFECCIONES COMPROBADAS EN VERTEBRADOS

NO HUMANOS, HUESPEDES DE Trypanosoma cruzi

\begin{tabular}{|c|c|c|c|c|c|}
\hline Nombre & Autor & Año & Localidad & Infec. & Ref. Biblil. \\
\hline $\begin{array}{l}\text { Didelphys marsupialis } \\
\text { (tlacuache) }\end{array}$ & $\begin{array}{l}\text { Dias, Perrin y } \\
\text { Brenes }\end{array}$ & 1947 & $\begin{array}{l}\text { Agua Buena, } \\
\text { Mich. }\end{array}$ & + & $(16)(51)$ \\
\hline \multirow[t]{2}{*}{$\begin{array}{l}\text { Dasypus novecinctus } \\
\text { mexicanus (armadillo) }\end{array}$} & $\begin{array}{l}\text { Ryckman y cols. } \\
\text { Mazzotti y Dias }\end{array}$ & $\begin{array}{l}1940 \\
1949\end{array}$ & $\begin{array}{l}\text { Colima } \\
\text { Colima }\end{array}$ & $\begin{array}{l}+ \\
+\end{array}$ & $\begin{array}{l}(58) \\
(34)\end{array}$ \\
\hline & Biagi y Tay & 1964 & Tetitlán, Gro. & + & $(11)$ \\
\hline \multirow[t]{2}{*}{ Canis familiaris (perro) } & Mazzotti y Dias & 1949 & Tutu tepec, Oax. & + & (34) \\
\hline & Velasco, $\mathrm{O}$ & 1970 & Tepechitlán, Zac. & + & $(78)$ \\
\hline $\begin{array}{l}\text { Rattus norvegicus } \\
\text { (rata noruega) }\end{array}$ & Beltrán, E. & 1949 & $\begin{array}{l}\text { Ciudad de México } \\
\text { (Mercado) }\end{array}$ & + & (6) \\
\hline
\end{tabular}

TABLA No. 4

ESTUDIO SOBRE LA ENFERMEDAD DE CHAGAS EN EL MUNICIPIO DE ZOCOALCO, JAL.

RESERVORIOS COLECTADOS EN LOS VIAJES DE ESTUDIO

\begin{tabular}{|c|c|c|c|c|c|}
\hline & $\begin{array}{l}\text { Nombre del } \\
\text { Animal }\end{array}$ & $\begin{array}{l}\text { Nombre } \\
\text { vulgar }\end{array}$ & $\begin{array}{l}\text { No. de animales } \\
\text { colectados }\end{array}$ & $\begin{array}{l}\text { No. de animales } \\
\text { positivos }\end{array}$ & $\%$ \\
\hline Reservorios & $\begin{array}{l}\text { Mus musculus } \\
\text { Rattus norvegicus } \\
\text { Scirus vulgaris } \\
\text { Canis familiaris }\end{array}$ & $\begin{array}{l}\text { ratón } \\
\text { rata } \\
\text { ardilla } \\
\text { perro }\end{array}$ & $\begin{array}{r}15 \\
5 \\
16 \\
125\end{array}$ & $\begin{array}{r}13 \\
2 \\
2 \\
0\end{array}$ & $\begin{array}{l}86.6 \\
40 \\
12.5\end{array}$ \\
\hline
\end{tabular}

Tay, J., Salazar, P.M., Velasco, M., Yañes, Y. y Haro A.I.

Depto. de Ecología Humana. Facultad de Medicina

U.N.A.M.

trabajos de Mazzotti, Biagi y Tay; Tay y cols., etc., se han reportado un número importante de localidades. Prácticamente encontramos triatóminos infectados por Trypanosoma cruzi en casi todos los estados de la República Mexicana, Mapa No. 2, aunque la mayor parte de las localidades se encuentran en la vertiente del Pacífico y en altitudes de 0 a 1800 metros sobre el nivel del mar (Mapa No. 3), lo que hace suponer que la zona probablemente endémica de enfermedad de Chagas sea muy amplia, casi las dos terceras partes del territorio nacional.

Actualmente se conocen 6 géneros del grupo Triatominae, el género Triatoma, con 36 especies $y$ subespecies, distribuídas prácticamente en toda lla República; el género Dipetalogaster con la especie maximus; el género Rhodnius con la especie prolixus; el género Paratriatoma con 3 especies: $P$. hirsuta papagoensis, $P . h$. yumanensis y $P$. h. kamiensis; recientemente, en comunicación personal (1977), el Dr. Dionisio Peláez, nos informó la presencia de Panstrongylus geniculatus y Eratyrus cuspidatus en el Estado de Veracruz. En los mapas Nos. 4 y 5 se ilustran las localidades donde se han encontrado especies del grupo Triatominae $y$ el número de ellas.

Es de hacer notar que un buen número de especies, sobre todo las del grupo phyllosoma, barberi, dimidiata y otras, se han encontrado y colectado dentro de la habitación humana infectadas por $T$. cruzi y con hábitos marcadamente intradomiciliarios; en ocasiones se han colectado en el momento mismo de estar picando a personas dormidas; así mismo, también se han colectado estos insectos en el 


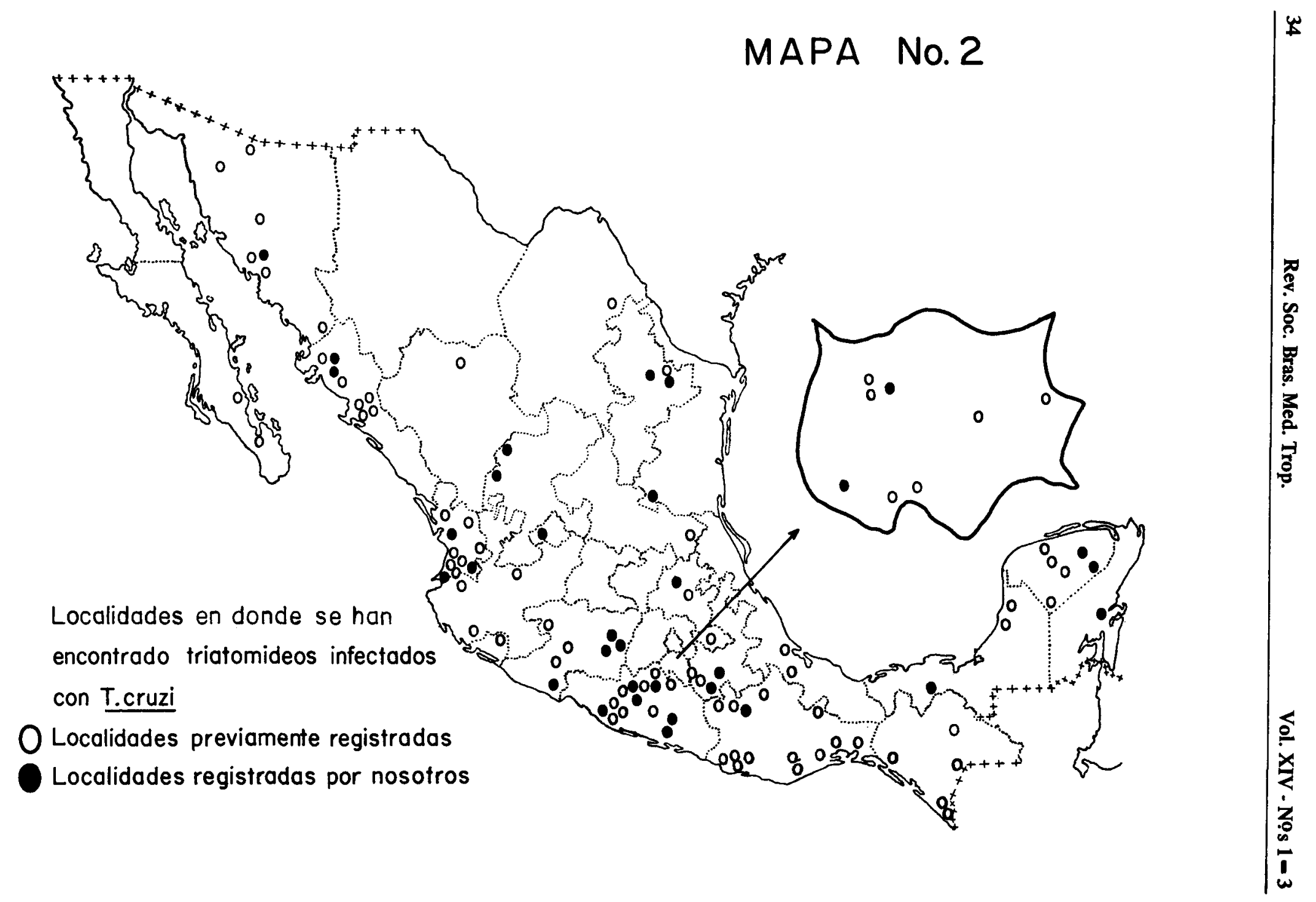




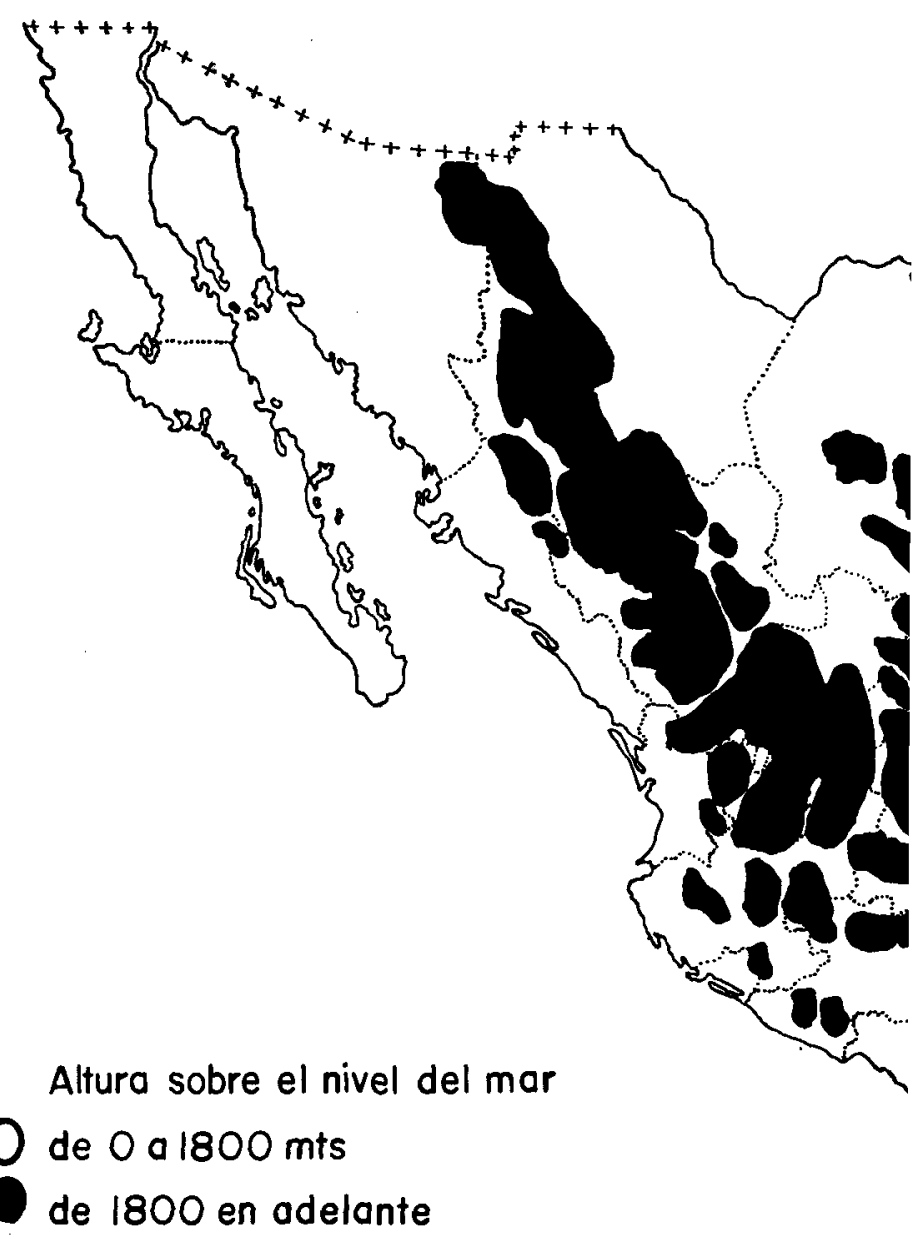




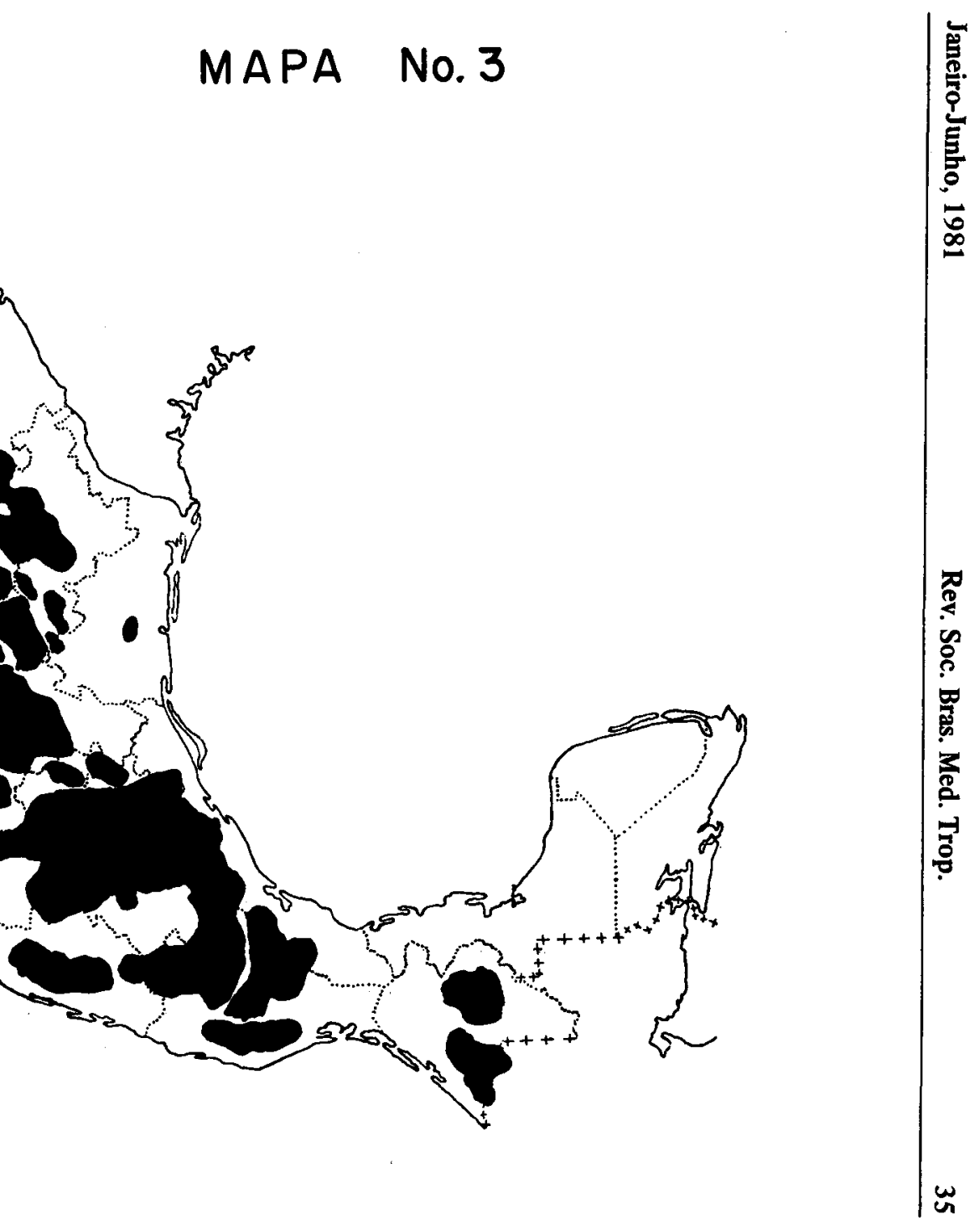




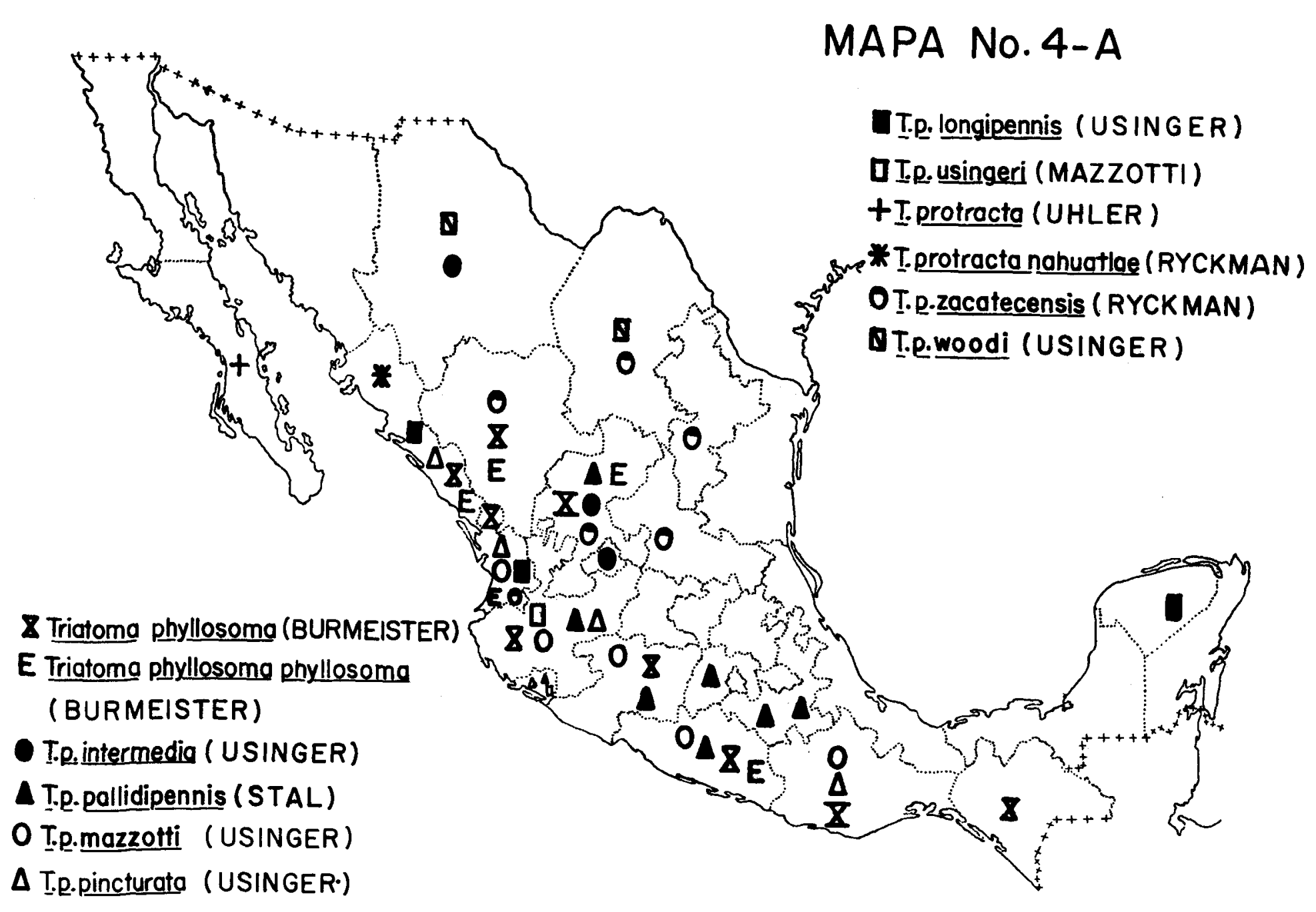


MAPA No.4-B

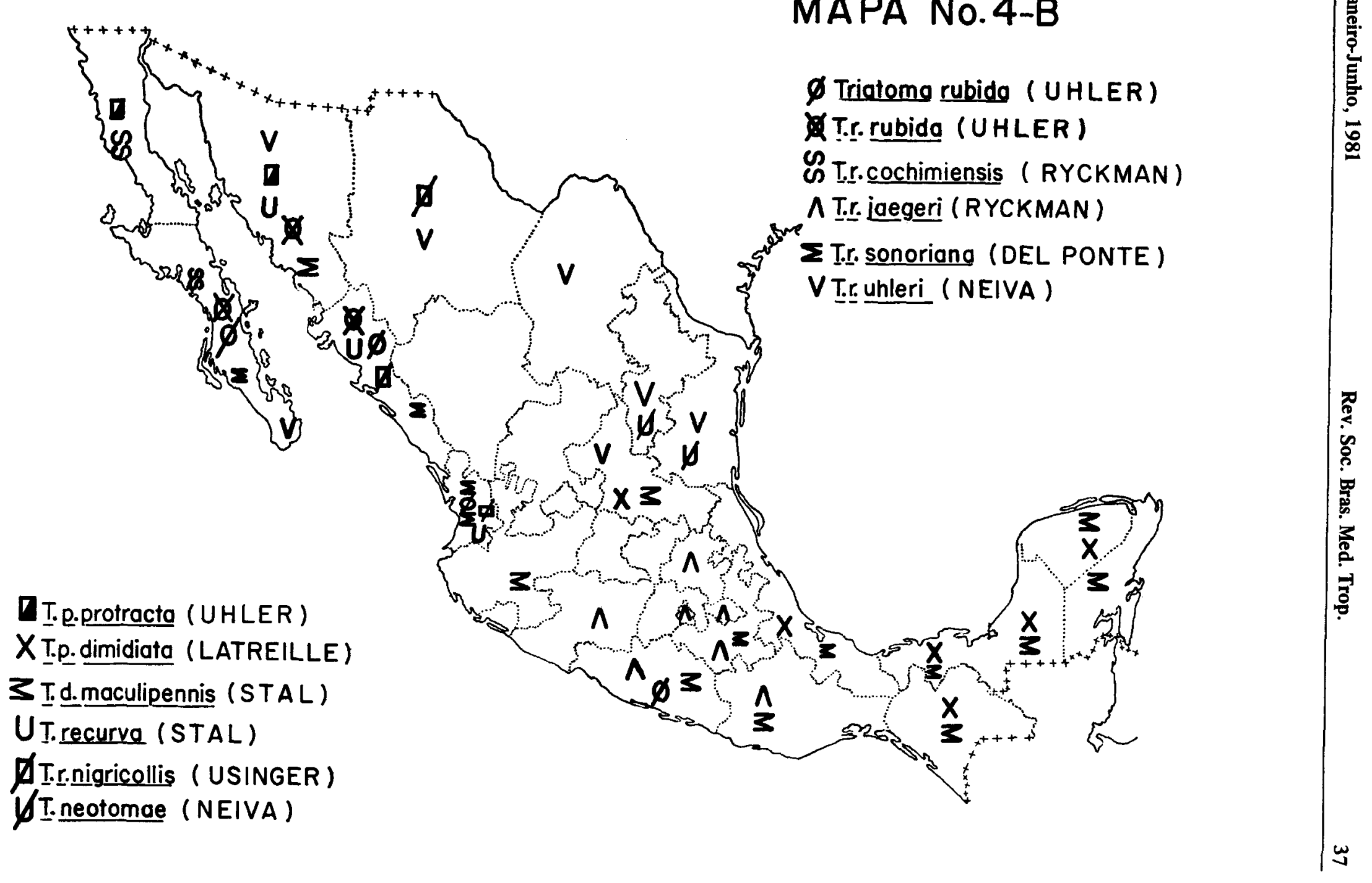




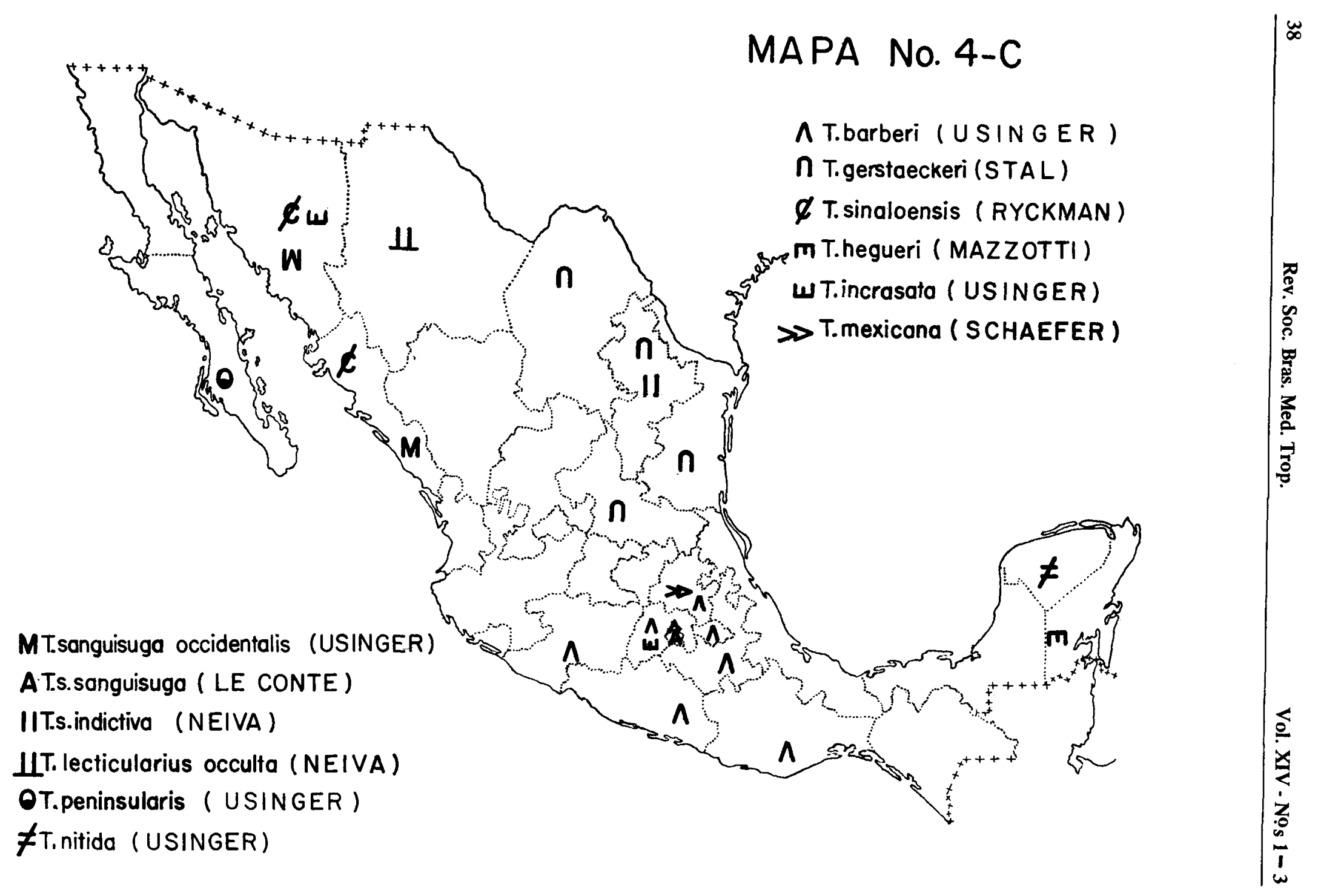




\section{MAPA No. 5}

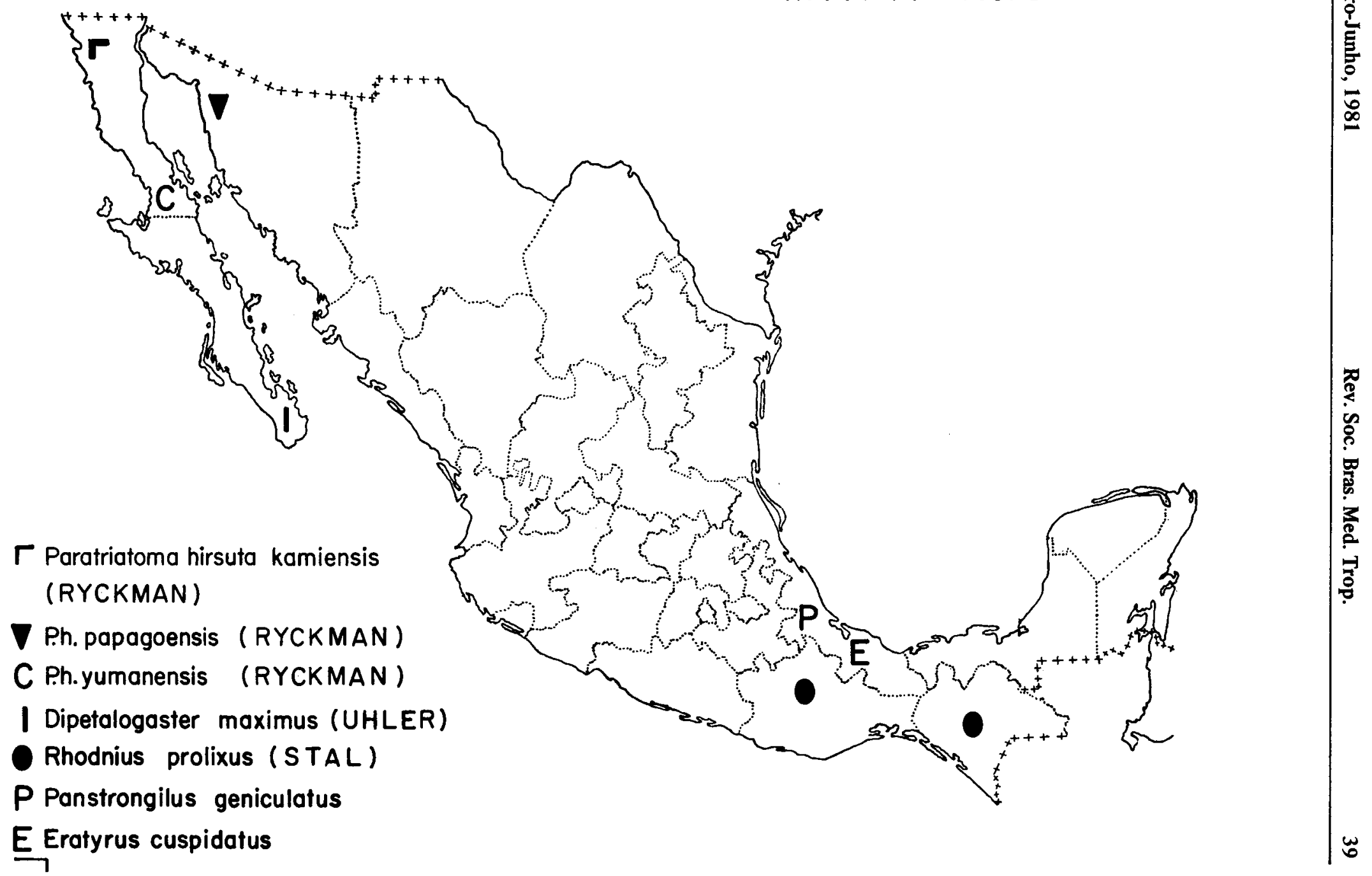


peridomicilio humano y en condiciones selváticas en nidos de animales selvajes.

Se han realizado estudios tendientes a demostrar la capacidad transmisora de algunas especies mexicanas, como el realizado por Little y Tay ${ }^{10}$, en el cual se demuestra que Triatoma phyllosoma pallidipennis y Triatoma barberi son capaces de efectuar la transmisión de $T$. cruzi muy favorablemente, aún en condiciones experimentales.

Durante las colectas de triatomineos y en las encuestas epidemiológicas que sobre enfermedad de Chagas se han venido realizando, hemos tenido la oportunidad de estudiar el comportamiento de diferentes cepas de Trypanosoma cruzi aisladas de distintas localidades.

En la Tabla No. 5 se señalan las distintas cepas, las localidades de donde se aislaron, si fueron aisladas en transmisores, en humanos, etc., así como el viscerotropismo preferencial de cada una de ellas. Como se puede ver en dicha Tabla, las cepas proceden de estados diferentes de la República; 9 de las 11 cepas fueron aisladas de heces de triatominos y 2 de casos humanos.

TABLA No. 5

CARACTERISTICAS DE LAS ONCE CEPAS DE Trypanosoma cruzi AISLADAS EN LA REPUBLICA MEXICANA Y ESTUDIADAS EN EL DEPTO. DE ECOLOGIA HUMANA

\begin{tabular}{|c|c|c|c|}
\hline Localidad de donde se aisló la cepa & Aislada de: & En: & $\begin{array}{l}\text { Viscerotropismo } \\
\text { preferente }\end{array}$ \\
\hline Tetitlán, Guerrero & Triatoma phyllosoma mazzotti & heces & Cardiotrópica \\
\hline $\begin{array}{l}\text { Estanzuela, Zacatecas } \\
\text { Las Higueras, Morelos } \\
\text { La Mesa, Michoacán } \\
\text { El Capulín, Michoacán } \\
\text { Jojutla, Morelos } \\
\text { Cocula, Jalisco } \\
\text { Santa Catarina, Jalisco }\end{array}$ & $\begin{array}{l}\text { Triatoma phyllosoma intermedia } \\
\text { Triatoma phyllosoma pallidipennis } \\
\text { Triatoma barberi } \\
\text { Triatoma barberi } \\
\text { sangre humana } \\
\text { Triatoma barberi } \\
\text { Triatoma barberi }\end{array}$ & $\begin{array}{l}\text { heces } \\
\text { heces } \\
\text { heces } \\
\text { heces } \\
\text { cultivo } \\
\text { heces } \\
\text { heces }\end{array}$ & $\begin{array}{l}\text { Cardiotrópica } \\
\text { Miotrópica } \\
\text { Cardio y Miotrópica } \\
\text { Miotrópica } \\
\text { Miotrópica } \\
\text { Cardiotrópica } \\
\text { Cardiotrópica }\end{array}$ \\
\hline $\begin{array}{l}\text { La Cruz, Jalisco } \\
\text { Zacoalco, Jalisco } \\
\text { Santa Catarina (Apodaca) }\end{array}$ & $\begin{array}{l}\text { Triatoma barberi } \\
\text { Triatoma barberi } \\
\text { sangre humana }\end{array}$ & $\begin{array}{l}\text { heces } \\
\text { heces } \\
\text { xeno }\end{array}$ & $\begin{array}{l}\text { Miotrópica } \\
\text { Miotrópica } \\
\text { Cardiotrópica }\end{array}$ \\
\hline
\end{tabular}

\section{ESTUDIOS SOBRE CEPAS DE Trypanosoma cruzi}

\section{AISLADAS EN LA REPUBLICA MEXICANA}

Dichas cepas fueron inoculadas en ratón blanco en dosis de $1 \times 10^{6}$ tripomastigotes por $\mathrm{ml}$ de sangre, por via intraperitoneal. A los ratones se les determinó el grado de parasitemia que desarrolaron durante su estudio y que fué en un lapso de 30 dias. La cuenta de tripomastigotes se hizo en cámara de Neubauer, empleaudo las pipetas de glóbulos blancos; se obtuvieron promedios de todos ellos, como lo observamos en la gráfica No. 1 en donde se ve lo que ya se ha comentado con anterioridad, acerca de que las cepas aisladas de humano, tienen una virulencia incrementada, cosa que observamos en las cepas de Jojutla y Apodaca, ambas aisladas de sangre humana, en las cuales sus promedios de parasitemia son los más elevados: $16 \times 10^{6}$ y $25 \times 10^{6}$ tripomastigotes por $\mathrm{ml}$ de sangre, res- pectivamente, comparándolas con las parasitemias que se obtuvieron con las cepas aisladas de triatominos.

Otro dato interesante es que las cepas cuyo tropismo preferencial es hacia el corazón, fueron a isladas en lugares donde se han encontrado casos humanos, mientras que en las que su tropismo en preferentemente hacia músculo esquelético, con excepción de la cepa de Jojutla, no se han encontrado casos humanos.

Se han efectuado estudios sobre órganos resecados a ratones inoculados con las cepas y que fueron: cerebro, corazón, músculo, esófago, ganglio, bazo, hígado y páncreas, y en los que básicamente se buscaron nidos de amastigotes por 100 campos microscópicos, así como alteraciones morfológicas en cada órgano.

Con las primeras 5 cepas, como vemos en la Tabla No. 5, se encontraron nidos en: corazón, músculo, esófago y ganglio, con las cepas Jojut la y Tetitlán, además de nidos en los anteriores órganos, se encontraron también en cerebro. 
JOJUTLA, MOR.

TETITLAN, GRO.

LAS HIGUERAS, MOR.

LA MESA, MICH.

EL CAPULIN, MICH.

ESTANZUELA, ZAC.

COCULA, JAL.

APODACA, JAL.

LA ORUZ, JAL.

ZACOALCO , JAL.

SANTA CATARINA, JAL.

\section{GRAFICA DE LOS PROMEDIOS DE LAS \\ PARASITEMIAS PRODUCIDAS POR LAS \\ CEPAS DE T.CRUZI EN EL RATON}

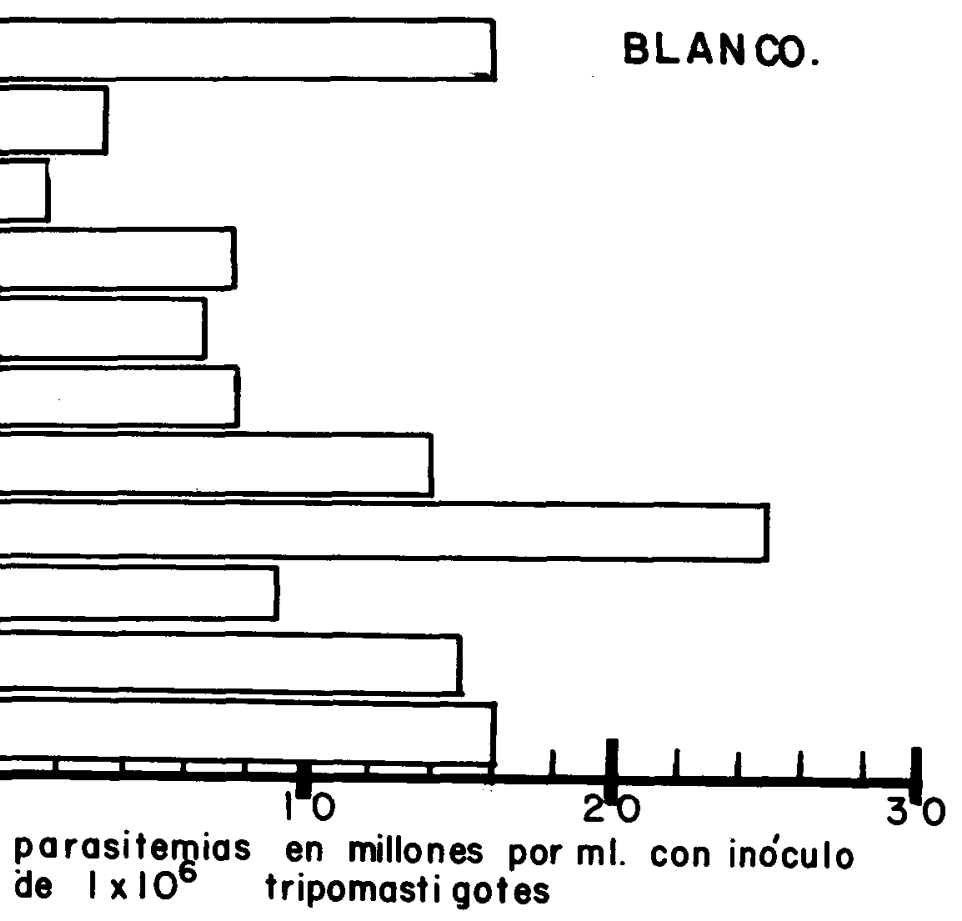

Grofico Nal
Con la cepa Cocula, se encontraron nidos de amastigotes en todos los órganos y cabe mencionar que en corazón se obtuvo un $100 \%$ de positividad, por lo cual se dice que es una cepa fuertemente cardiotrópica.

En cuanto a los cambios histopatológicos de las primeras 7 cepas (Tabla No. 5), los cambios comunes que se encontraron en los animales inoculados con estas cepas fueron: la estructura más afectada fué músculo esquelético, el cual mostró densos infiltrados inflamatorios periflevíticos en el parénquima; con las cepas La Mesa y Cocula, se vieron extensas necrosis, sobre todo en la última, en la cual se encontraron además, campos con nidos de amastigotes grandes y múltiples en corazón, mientras que en las anteriores el corazón presentó menor cantidad de infiltrados.

Las cuatro últimas cepas de la gráfica número 1 , se aislaron en un municipio del Estado de Jalisco, durante el desarrollo de una investiga- ción epidemiológica hecha en este lugar, con el fin de hacer un estudio comparativo de cepas a isladas en lugares cercanos, siendo el resultado el que se presenta en este trabajo, como ejemplo de estudio de cepas.

Para valorar la virulencia de las diferentes cepas de $T$. cruzi aisladas de un caso humano por xenodiagnóstico, y de 3 adultos de $T$. barberi, se inoculó con deyecciones de los triatomas al ratón blanco y de éstos se obtuvo un concentrado de $1 \times 10^{7}$ tripomastigotes sanguíneos por $\mathrm{ml}$ de cada una de las cepas $y$ con el cual se inocularon lotes de 10 ratones blancos, en cada caso, con cantidades de $1 \times 10^{6}$ tripomastigotes sanguíneos a cada ratón; los ratones se revisaron en días alternos durante 30 días, utilizando para esto la cámara de Neubauer; cumplido este tiempo, o bien en cuanto murieron, se les practicó necropsia, para estudio histopatológico y recuento de nidos de amastigotes de 8 órganos, que fueron los si- 
MAPA No. 6

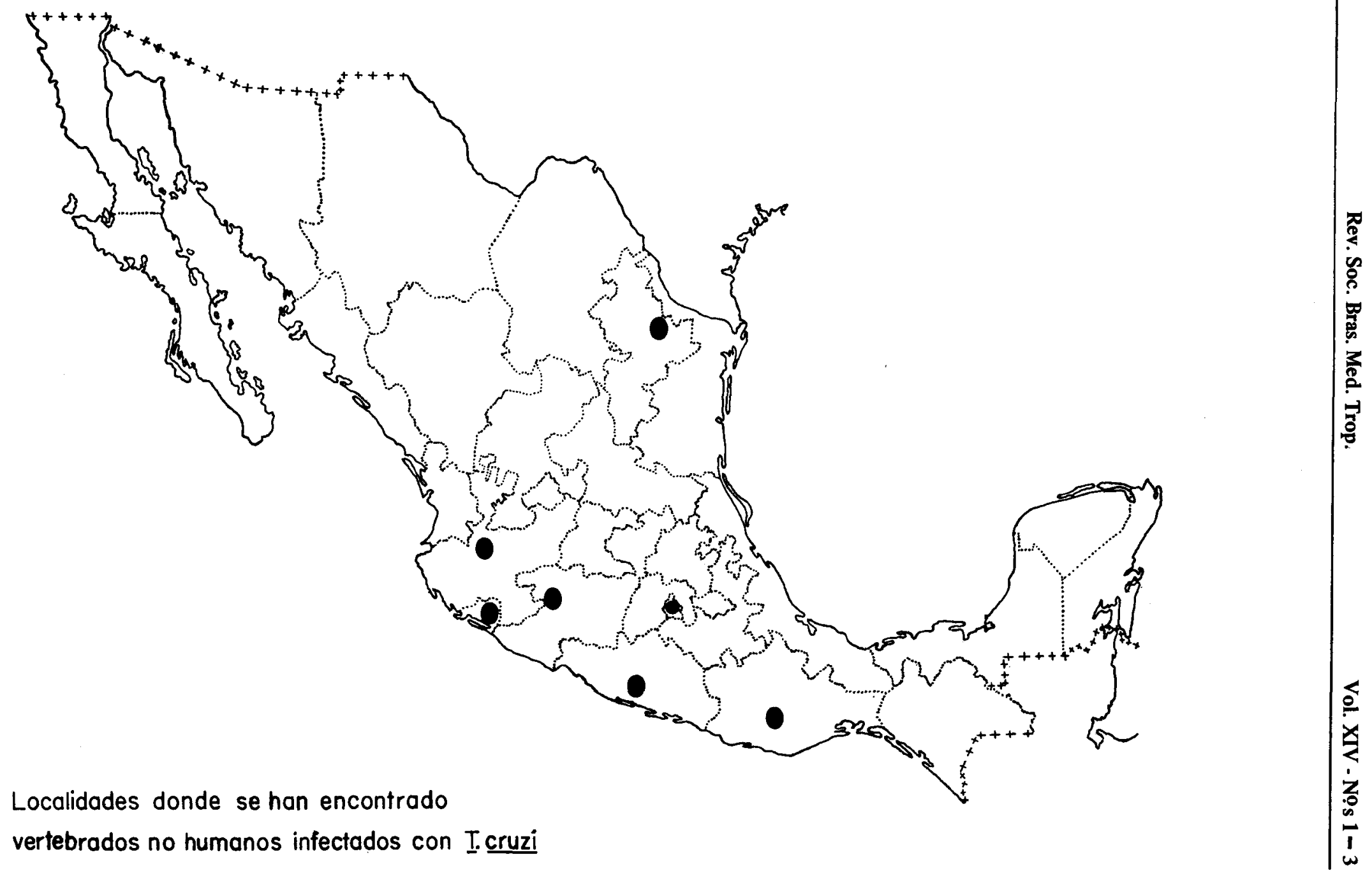


guientes: corazón, esófago, pulmón, bazo, cerebro, páncreas, ganglio linfático $y$ gastronemio.

Se lograron aislar 4 cepas de T. cruzi; una del caso humano detectado por xenodiagnóstico, la que se denominó con el apellido del paciente: "Apodaca", y las otras 3 de triatomas colectados en las comunidades de Santa Catarina, La Cruz y Zacoalco, nombres que se les asigna. ron, respect ivamente.

De cada una de estas cepas se realizaron los estudios ya señalados anteriormente, obteniendo los siguientes resultados:

A) En la cepa Apodaca laislada por xenodiagnóstico), se obtuvo la parasitemia más elevada, 4. $0 \times 10^{7}$ tripomastigotes por $\mathrm{ml}$. Estos se hicieron presentes al 69 día de la inoculación y al 21 ? día, todos los ratones murieron. En cuanto a la presencia $y$ abundancia de los nidos de amastigotes, fué en miocardio, músculo estríado, esófago, cerebro, hígado y pulmón, donde se encontraron, en orden decreciente de abundancia. En el miocardio, de los 10 ratones estudiados se encontraron como promedio 230 nidos de amastigotes, cifra que se considera como base para juzgar comparativamente la abundancia de nidos en los demás órganos.

El patrón histológico que se observó en miocardio fué de densos infiltrados linfocitarios, formando acúmulos o disociando las fibras que se aprecian notablemente destruídas; en todos los demás órganos se encontró este tipo de alteración, excepto en bazo, donde se apreció congestión en pulpa roja.

B) De las cepas aisladas del transmisor, la Santa Catarina fué la más virulenta y la que produjo las más altas parasitemias, con $3.5 \times 10^{7}$ tripomastigotes por $\mathrm{ml}$ (de este lugar son 4 de los casos humanos detectados). La aparición de la parasitemia fué al 60 día de la inoculación, muriendo 8 ratones al 21 Q día y los 2 restantes antes del mes. Respecto a su ubicación y abundancia visceral, se encontró que en miocardio, músculo estríado, esófago, pulmón e hígado, se detectaron nidos de amastigotes en orden decreciente.

El cuadro histopatológico que presentaron fué de gran alteración del músculo con densos infiltrados, predominantemente linfocitarios, células en picnosis, áreas de destrucción con deshilachamiento de miofibrillas; las zonas hialinizadas y neovascularizadas en pulmón. En miocardio se observó exudado inflamatorio difuso poco abundante, formado por linfocitos principalmente, en hígado, gran congestión vascular, pleomorfismo celular en hepatocitos, con gigantismo e hipercromatismo nuclear. En los órganos restantes no hay alteración aparente.

C) La cepa Zacoalco, mostró, mediante virulencia comparada con las otras, una parasitemia máxima de $2.9 \times 10^{7}$ tripomastigotes por $\mathrm{ml}$. Estos hicieron su aparición al 3er. día de la inoculación y se mantuvieron así los 30 días de estudio, sobreviviendo todos. En el estudio histopatológico, se observaron escasos nidos de amastigotes, con infiltrado linfocitario en todos los órganos y congestión de pulpa roja y hemorragia en bazo.

D) En la cepa La Cruz, que resultó la menos virulenta, la parasitemia más alta fué de $1.7 x$ $10^{7}$ tripomastigotes por $\mathrm{ml}$, apareciendo éstos hasta el 9 ? día y persistiendo los 30 días que se mantuvieron en estudio. En su ubicación tisular, sólo se encontraron en músculo estríado, miocardio y esófago, en orden decreciente de abundancia $y$ con una imagen histopatológica de discreto infiltrado linfocitario en todos los órganos y congestión de pulpa roja, con discreta desorganización de la blanca en bazo.

\section{OTROS ESTUDIOS}

Con cepas mexicanas de Trypanosoma cruzi, se han realizado estudios tendientes a demostrar su capacidad invasora al huésped vertebrado por diferentes vías de inoculación, Ortega y Tay $^{36}$; así como el comportamiento de dichas cepas al hacerlas pasar del huésped mamífero al transmisor y de éste nuevamente al mamífero, Tay y cols. 70 , lo que ha permitido conocer, al menos en parte, la conducta que quizá siguen cepas mexicanas en las infecciones naturales.

Cabe señalar que se han hecho estudios tendientes a obtener protección de animales de experimentación a la infección por Trypanosoma cruzi, mediante inoculaciones previas de fracciones de los parásitos o a los parásitos mismos, como lo hicieron Garcia y cols. en 1975 18 ; así como el papel que juegan el sexo y las hormonas en el curso de las infecciones experimentales por Trypanosoma cruzi, Tay y cols. 
CUADRO No. 1

TRIATOMINOS EN MEXICO

Triatoma dimidiata maculipennis

(Stal, 1859)

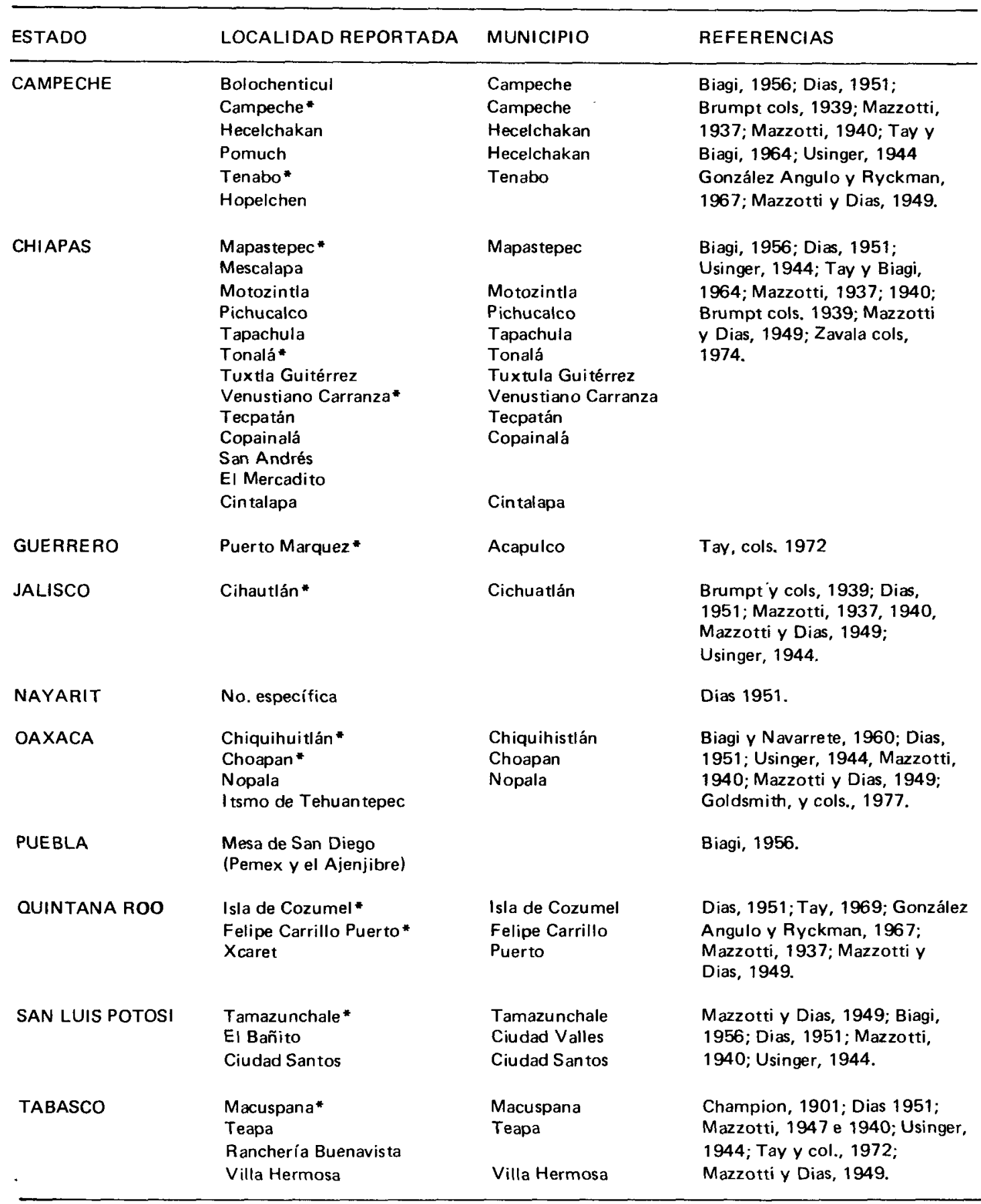

* Infección natural com $T$. cruzi. 
CUADRONO. 1

TRIATOMINOS EN MEXICO

Triatoma dimidiata maculipennis

(Stal, 1859)

(cont.)

\begin{tabular}{|c|c|c|c|}
\hline ESTADO & LOCALIDAD REPORTADA & MUNICIPIO & REFERENCIAS \\
\hline VERACRUZ & $\begin{array}{l}\text { Córdoba } \\
\text { Cuesta de Misantla } \\
\text { Nanchital } \\
\text { Tempoal } \\
\text { Tierra Blanca* } \\
\text { Tantoyuca } \\
\text { San Andrés Tuxtla } \\
\text { Veracruz* } \\
\text { Actopan } \\
\text { Aguacate } \\
\text { La Ceiba } \\
\text { Camarones } \\
\text { Catemaco }\end{array}$ & $\begin{array}{l}\text { Córdoba } \\
\text { Min } \\
\text { Minatitlán } \\
\text { Tempoal } \\
\text { Tierra Blanca } \\
\text { Tantoyuca } \\
\text { San Andrés Tuxtla } \\
\text { Veracruz } \\
\text { Actopan }\end{array}$ & $\begin{array}{l}\text { Mazzotti, 1937, 1940; } \\
\text { Champion, 1901; Dias, 1951; } \\
\text { Bernal Flandes, 1938; Brumpt y } \\
\text { col, 1939; Biagi y Navarrete, } \\
\text { 1960; Hoffman, 1928; Usinger, } \\
\text { 1944; Biagi, 1956; Hernândez } \\
\text { Lira, 1965; Mazzotti y Dias, } \\
\text { 1949. }\end{array}$ \\
\hline YUCATAN & $\begin{array}{l}\text { Dzitas } \\
\text { Uxmal } \\
\text { Temax } \\
\text { Valladolid } \\
\text { Mérida* } \\
\text { Pacabtún* } \\
\text { Peto* } \\
\text { Progreso } \\
\text { Texmeuac } \\
\text { Ticul* } \\
\text { Chichen Itza } \\
\text { Oxkytzcab* } \\
\text { Tekax } \\
\text { Yaxcopoilt } \\
\text { Muna } \\
\text { Thacmec } \\
\text { Cantunil* } \\
\text { Izamal } \\
\text { San Antonio de Zizcal } \\
\text { San Pedro Nohpat* } \\
\text { Ticopó } \\
\text { Tella* } \\
\text { Ticul* } \\
\text { Timún* } \\
\text { Chabihau * } \\
\text { Motul } \\
\text { Dzemul } \\
\text { Tinúm* } \\
\text { Hunucma* } \\
\text { Kipoma* } \\
\text { Tekax* } \\
\text { Belca* } \\
\text { Balacho } \\
\text { Baca } \\
\text { Cenotillo } \\
\text { Itzincab } \\
\text { Ticul } \\
\text { That }\end{array}$ & $\begin{array}{l}\text { Dzitas } \\
\text { Santa Elena } \\
\text { Temax } \\
\text { Valladolid } \\
\text { Mérida } \\
\text { Peto } \\
\text { Progreso } \\
\text { Texmeuac } \\
\text { Ticul } \\
\text { Tinum } \\
\text { Oxkutzcam } \\
\text { Tekax } \\
\text { Peto } \\
\text { Muna } \\
\text { Thacmec } \\
\\
\text { Izamal } \\
\text { Kanacín } \\
\text { Tecoh } \\
\text { Tella } \\
\text { Ticul } \\
\text { Motul } \\
\text { Yoabain } \\
\text { Motul } \\
\text { Dzemul } \\
\text { Tinúm } \\
\text { Hunucma } \\
\text { Kipoma } \\
\text { Tekax } \\
\text { Baca } \\
\text { Cenotillo } \\
\text { Ticul } \\
\text { Thang }\end{array}$ & $\begin{array}{l}\text { Champion, 1901; Dias, 1951; } \\
\text { Brumpt, y cols., 1939; Usinger, } \\
\text { 1944; Mazzotti, 1937; Tay y } \\
\text { Biagi, 1964; Biagi, 1956; } \\
\text { González Angulo y Ryckman, } \\
\text { 1967; Quintanal y Planco, } \\
\text { 1977; Mazzotti y Dias, 1949; } \\
\text { Ryxkmar, 1967; Tay, } \\
\text { 1969; Palomo, 1940; Zavala y } \\
\text { col., 1974. }\end{array}$ \\
\hline
\end{tabular}


CUADRO No. 2

TRIATOMINOS EN MEXICO

Triatoma barberi

(Usinger, 1939)

\begin{tabular}{|c|c|c|c|}
\hline ESTADO & LOCALIDAD REPORTADA & MUNICIPIO & REFERENCIAS \\
\hline GUERRERO & $\begin{array}{l}\text { Huamustitlán } \\
\text { Olinalá* } \\
\text { Iguala }\end{array}$ & $\begin{array}{l}\text { Huamustitlán } \\
\text { Olinalá } \\
\text { Iguala }\end{array}$ & $\begin{array}{l}\text { Little y cols, 1966; Mazzot ti, } \\
\text { 1939, 1940, 1940, 1940, } \\
\text { Mazzotti y Dias, 1949; Dias, } \\
\text { 1951; Biagi, 1956; Perrín, } \\
\text { 1949; Brumpt y cols, 1939; } \\
\text { Fyckman, 1962; Usinger, } \\
\text { 1944. }\end{array}$ \\
\hline HIDALGO & $\begin{array}{l}\text { Metztitlán* } \\
\text { Santiago de Anaya }\end{array}$ & $\begin{array}{l}\text { Metztitlán } \\
\text { Santiago de Anaya }\end{array}$ & $\begin{array}{l}\text { Little y cols., 1966; Ryckman, } \\
\text { 1962; Dias, 1951; Mazzotti, } \\
\text { 1940; Usinger, 1944; Mazzotti } \\
\text { y Dias, 1949. }\end{array}$ \\
\hline JALISCO & $\begin{array}{l}\text { Zacoalco de Torres* } \\
\text { Sta. Catarina* } \\
\text { La,Cruz* }\end{array}$ & $\begin{array}{l}\text { Zacoalco de Torres } \\
\text { Zacoalco de Torres } \\
\text { Zacoalco de Torres }\end{array}$ & Tay y cols., 1976 \\
\hline MEXICO & Distri to Federal & & $\begin{array}{l}\text { Dias, 1951; Usinger, 1944; } \\
\text { Little y cols, 1966; Ryckman, } \\
1962 .\end{array}$ \\
\hline MICHOACAN & $\begin{array}{l}\text { El Capulín } \\
\text { La Mesa* } \\
\text { Milpillas* } \\
\text { El Malacate* } \\
\text { Tuxpán* } \\
\text { Huirunio }\end{array}$ & $\begin{array}{l}\text { Tuxpán } \\
\text { Tuxpán } \\
\text { Tuxpán } \\
\text { Tuxpán } \\
\text { Tuxpán } \\
\text { Tuxpán }\end{array}$ & $\begin{array}{l}\text { Little y cols., 1966; Tay y } \\
\text { Biagi, 1964; Tay y cols., 1966, } \\
\text { 1967, 1973. }\end{array}$ \\
\hline MORELOS & $\begin{array}{l}\text { Cuernavaca } \\
\text { Temixco } \\
\text { Villa Ayala* } \\
\text { Zacoalpan de milpas* }\end{array}$ & $\begin{array}{l}\text { Cuernavaca } \\
\text { Temixco } \\
\text { Villa Ayala } \\
\text { Zacoalpan de Amilpas }\end{array}$ & $\begin{array}{l}\text { Ryckman, 1962, Tay y cols., } \\
\text { 1966; Usinger, 1939, 1944; } \\
\text { Mazzotti, 1940; Dias, 1951; } \\
\text { Tay y Biagi, 1964; Mazzotti y } \\
\text { Dias, 1949. }\end{array}$ \\
\hline & $\begin{array}{l}\text { Jojutla* } \\
\text { Axochiapan* } \\
\text { Tilzapotla* } \\
\text { Las Higueras } \\
\text { Chiconcuac* } \\
\text { Acatipla* }\end{array}$ & $\begin{array}{l}\text { Jojutla } \\
\text { Axochiapan } \\
\text { Puente de Ixtla } \\
\text { Temixco } \\
\text { Xochitepec } \\
\text { Actipla }\end{array}$ & $\begin{array}{l}\text { Little y cols., 1966; Gonźalez } \\
\text { Hernández y cols., } 1972 .\end{array}$ \\
\hline OAXACA & $\begin{array}{l}\text { Tepelmeme* } \\
\text { Madgalena de Apazco* } \\
\text { Sola de Vega* } \\
\text { Cuicatlán }\end{array}$ & $\begin{array}{l}\text { Tepelmeme } \\
\text { Apazco } \\
\text { Sola de Vega } \\
\text { Cuicatlán }\end{array}$ & $\begin{array}{l}\text { Brumpt y cols., 1939; Ryckman } \\
\text { y cols., 1965, 1962; Dias, 1951; } \\
\text { Mazzotti, 1938, 1939, 1940; } \\
\text { Biagi, 1956; Brodie y Ryckman, } \\
\text { 1967; Little y cols., 1966; } \\
\text { Mazzotti y Dias, 1949; Usinger, } \\
\text { 1944; Zárate y cols. (no pub.); } \\
\text { Tay, 1969. }\end{array}$ \\
\hline PUEBLA & $\begin{array}{l}\text { Chietla } \\
\text { Puebla } \\
\text { Tecomatlán } \\
\text { Piaxtla }\end{array}$ & $\begin{array}{l}\text { Chietla } \\
\text { Puebla } \\
\text { Tecomatlán } \\
\text { Piaxtla }\end{array}$ & $\begin{array}{l}\text { Biagi, 1956; Little y cols., } \\
\text { 1966; Ryckman, } 1962 .\end{array}$ \\
\hline TLAXCALA & $\begin{array}{l}\text { San Cosme Mezatecozco* } \\
\text { San Francisco Papalota }\end{array}$ & $\begin{array}{l}\text { San Comes Mezatecozco } \\
\text { San Francisco Papalota }\end{array}$ & Tay, 1969 \\
\hline
\end{tabular}

* Infección natural con T. cruzi. 
CUADRO No. 3

TRIATOMINOS EN MEXICO

Triatoma gerstaeckeri

(Stal 1859)

\begin{tabular}{|c|c|c|c|}
\hline ESTADO & LOCALIDAD REPORTADA & MUNICIPIO & REFERENCIAS \\
\hline COAHUILA & Sabinas* & Sabinas & $\begin{array}{l}\text { Mazzotti, 1947; Aguirre } \\
\text { Pequeño, 1947; Mazzotti y Dias, } \\
\text { 1949; Dias, 1951. }\end{array}$ \\
\hline NUEVO LEON & $\begin{array}{l}\text { Monterrey } \\
\text { General Bravo* }\end{array}$ & $\begin{array}{l}\text { Monterrey } \\
\text { General Bravo }\end{array}$ & $\begin{array}{l}\text { Aguirre Pequeño, 1947; } \\
\text { Mazzotti y Dias, 1949; Tay, } \\
\text { 1969; Dias, 1951; Usinger, } \\
\text { 1944. }\end{array}$ \\
\hline SAN LUIS POTOSI & Presa de Guadalupe & & Tay, 1969. \\
\hline TAMAULIPAS & $\begin{array}{l}\text { Soto de la Marina } \\
\text { Tula* } \\
\text { Nueva Ciudad Guerrero } \\
\text { Los Cerritos } \\
\text { Estación Ramírez }\end{array}$ & $\begin{array}{l}\text { Soto de la Marina } \\
\text { Tula }\end{array}$ & $\begin{array}{l}\text { Aguirre Pequeño, 1947; } \\
\text { Mazzotti y Dias, 1949; Dias, } \\
\text { 1951: Tay, 1969; Tay y Biagi, } \\
\text { 1964. }\end{array}$ \\
\hline
\end{tabular}

* Infección natural con $T$. cruzi.

CUADRO No. 4

TRIATOMINOS EN MEXICO

Triatoma hegneri

(Mazzotti, 1940)

\begin{tabular}{llll}
\hline ESTADO & LOCALIDAD REPORTADA & MUNICIPIO & REFERENCIAS \\
\hline QUINTANA ROO & $\begin{array}{l}\text { Isla de Cozumel* } \\
\text { (Rancho Nuevo, } \\
\text { Rancho Santa Rita* } \\
\text { El Cedral). }\end{array}$ & Isla de Cozumel & $\begin{array}{l}\text { Dias, 1951; Usinger, 1944; } \\
\text { Mazzotti, 1943, 1940; } \\
\text { Mazzotti y Dias, 1949; González } \\
\end{array}$ \\
\hline
\end{tabular}

\footnotetext{
- Infección natural con T. cruzi.
}

\section{CUADRO No. 5}

TRIATOMINOS EN MEXICO

Triatoma incrassata

(Usinger, 1939)

\begin{tabular}{|c|c|c|c|}
\hline ESTADO & LOCALIDAD REPORTADA & MUNICIPIO & REFERENCIAS \\
\hline MEXICO & Valle de México & & $\begin{array}{l}\text { Usinger, 1939, 1944; Dias, } \\
\text { 1951; Mazzotti, 1940; Mazzotti } \\
\text { y Dias, } 1949 .\end{array}$ \\
\hline SONORA & Santa Barbara & & $\begin{array}{l}\text { Usinger, 1944; Dias, } 1951 \text {; } \\
\text { Mazzotti, 1940; Mazzotti } y \\
\text { Dias, } 1949 .\end{array}$ \\
\hline
\end{tabular}


CUADRO No. 6

TRIATOMINOS EN MEXICO

Triatoma lectularius occulta

(Neiva, 1911)

\begin{tabular}{llll}
\hline ESTADO & LOCALIDAD REPORTADA & MUNICIPIO & REFERENCIAS \\
\hline NUEVO LEON & $\begin{array}{l}\text { Monterrey } \\
\text { Municipio China* }\end{array}$ & $\begin{array}{l}\text { Monterrey } \\
\text { Municipio China }\end{array}$ & $\begin{array}{l}\text { Usinger, 1944; Dias, 1951; } \\
\text { Tay y cols., 1972; Mazzotti } \\
\text { y Dias, 1949. }\end{array}$ \\
\hline
\end{tabular}

- Infección natural con T. cruzi.

CUADRO NO. 7

TRIATOMINOS EN MEXICO

Triatoma mexicana

(Herrich-Schaeffer, 1848)

\begin{tabular}{|c|c|c|c|}
\hline ESTADO & LOCALIDAD REPORTADA & MUNICIPIO & REFERENCIAS \\
\hline HIDALGO & Metztitlán & & $\begin{array}{l}\text { Mazzotti, 1940; Usinger, 1944; } \\
\text { Dias, 1951; Mazzotti y Dias, } \\
1949 .\end{array}$ \\
\hline
\end{tabular}

CUADRO No. 8

TRIATOMINOS EN MEXICO

Triatoma neotomae

(Neiva, 1911)

\begin{tabular}{|c|c|c|c|}
\hline ESTADO & LOCALIDAD REPORTADA & MUNICIPIO & REFERENCIAS \\
\hline NUE VO LEON & $\begin{array}{l}\text { Sitios selváticos en tre } \\
\text { Laredo y Mon temorelos y } \\
\text { Sur de Mon terrey. }\end{array}$ & & $\begin{array}{l}\text { Ryckman, Comunicación } \\
\text { personal (12 julio 1976). }\end{array}$ \\
\hline TAMAULIPAS & Sitio selváticos. & & $\begin{array}{l}\text { Ryckman, comunicación } \\
\text { personal (12 de julio } 1976 \text { ). }\end{array}$ \\
\hline
\end{tabular}

CUADRO No. 9

TRIATOMINOS EN MEXICO

Triatoma nitida

(Usinger, 1939)

\begin{tabular}{llll}
\hline ESTADO & LOCALIDAD REPORTADA & MUNICIPIO & REFERENCIAS \\
\hline YUCATAN & Ticul* & Ticul & González Angulo y Ryckman, \\
& $8 \mathrm{~km}$ S Ticul* & Ticul & $1967 ;$ Ryckinan y Ryckman, \\
& & & 1967.
\end{tabular}

\footnotetext{
* Infección natural con $T$. cruzi.
} 
CUADRO No. 10

TRIATOMINOS EN MEXICO

Triatoma phyllosoma phyllosoma

(Burmeister, 1835)

\begin{tabular}{|c|c|c|c|}
\hline ESTADO & LOCALFDAD REPORTADA & MUNICIPIO & REFERENCIAS \\
\hline DURANGO & No especificada. & & Mazzotti y Dias, 1949. \\
\hline NAYARIT & $\begin{array}{l}\text { Trapiche* } \\
\text { Jalisco* } \\
\text { Ixtlán del Rio* } \\
\text { La Fortuna* } \\
\text { El Pantanal* } \\
\text { Lo de Olmedo* } \\
\text { El Venado }\end{array}$ & $\begin{array}{l}\text { Jalisco } \\
\text { Ixtlán del Rio }\end{array}$ & $\begin{array}{l}\text { Mazzotti, 1939, 1940, 1949, } \\
\text { 1940; Dias, 1951; Mazzotti y } \\
\text { Dias, 1949. }\end{array}$ \\
\hline \multirow[t]{2}{*}{ OAXACA } & $\begin{array}{l}\text { Juchitán * } \\
\text { Collantes* } \\
\text { Tehuantepec* } \\
\text { Totoloapan } \\
\text { Tututepec* } \\
\text { Santiago Pinotepa Nacional* }\end{array}$ & $\begin{array}{l}\text { Juchitán } \\
\text { Tehuantepec } \\
\text { Totoloapan } \\
\text { Tututepec } \\
\text { Santiago Pinotepa } \\
\text { Nacional }\end{array}$ & $\begin{array}{l}\text { Mazzotti, 1937, 1939, 1940; } \\
\text { Usinger, 1941; Mazzotti y Dias, } \\
\text { 1949; Mazzotti y Osorio, 1942; } \\
\text { Usinger, } 1944 .\end{array}$ \\
\hline & Cozal tepec* & Santa María Cozal tepec & \\
\hline SINALOA & No especificada. & & Mazzotti y Dias, 1949. \\
\hline ZACATECAS & No especificada. & & Mazzotti y Dias, 1949. \\
\hline
\end{tabular}

- Infección natural con T. cruzi.

CUADRO No. 11

TRIATOMINOS EN MEXICO

Triatoma phyllosoma intermedia

(Usinger, 1944)

\begin{tabular}{|c|c|c|c|}
\hline ESTADO & LOCALIDAD REPORTADA & MUNICIPIO & REFERENCIAS \\
\hline AGUASCALIENTES & Barranca de Portales* & Calvillo & Tay, 1969. \\
\hline CHIHUAHUA & Batopilas & Batopilas & Tay, 1969. \\
\hline ZACATECAS & $\begin{array}{l}\text { Juchipila } \\
\text { Momax * } \\
\text { Estanzuela * } \\
\text { Las Pilas* } \\
\text { Tovares* } \\
\text { Tepechitlán } \\
\text { Moyahua* } \\
\text { Apozol } \\
\text { Santa Juana } \\
\text { Huanusco* } \\
\text { Atotonilco* } \\
\text { Milpillas de Allende }\end{array}$ & $\begin{array}{l}\text { Juchipila } \\
\text { Momax } \\
\text { Rio Grande } \\
\text { Tepechitlán } \\
\text { Moyahua } \\
\text { Apozol } \\
\text { Jalpa } \\
\text { Huanusco } \\
\text { Valparaíso } \\
\text { Teúl de González O. }\end{array}$ & $\begin{array}{l}\text { Tay, 1969; Dias, 1951; } \\
\text { Usinger, 1944; Mazzotti y } \\
\text { Dias, 1949; Tay y Biagi, 1964; } \\
\text { Little y cols., 1968, 1972, } \\
\text { 1973; Velasco Cas trejón y } \\
\text { cols. }\end{array}$ \\
\hline
\end{tabular}

* Infección natural con T. cruzi. 
CUADRO No. 12

TRIATOMINOS EN MEXICO

Triatoma phyllosoma longipennis

(Usinger 1939)

\begin{tabular}{|c|c|c|c|}
\hline ESTADO & LOCALIDAD REPORTADA & MUNICIPIO & REFERENCIAS \\
\hline NAYARIT & $\begin{array}{l}\text { Tepic* } \\
\text { Trapiche* }\end{array}$ & Tepic & $\begin{array}{l}\text { Mazzotti, 1949; Dias, 1951; } \\
\text { Mazzotti y Dias, } 1949 .\end{array}$ \\
\hline SINALOA & $\begin{array}{l}\text { Venedio } \\
\text { Mazatlán } \\
\text { Elota }\end{array}$ & $\begin{array}{l}\text { Mazatlán } \\
\text { Elota }\end{array}$ & $\begin{array}{l}\text { Usinger, 1939, 1941, 1944; } \\
\text { Dias, 1951; Biagi y Navarrete, } \\
\text { 1960; Mazzotti y Dias, 1949; } \\
\text { Mazzotti, } 1940 .\end{array}$ \\
\hline YUCATAN & Kanasin & Kanasin & $\begin{array}{l}\text { Zarate, 1977, comunicación } \\
\text { personal. }\end{array}$ \\
\hline
\end{tabular}

* Infección con T. cruzi.

CUADRO No. 13

TRIATOMINOS EN MEXICO

Triatoma phyllosoma mazzotti

(Usinger, 1941)

\begin{tabular}{|c|c|c|c|}
\hline ESTADO & LOCALIDAD REPORTADA & MUNICIPIO & REFERENCIAS \\
\hline GUERRERO & $\begin{array}{l}\text { Tetitlán } \\
\text { Ejido Primera Agua } \\
\text { Tecpán de Galeana }\end{array}$ & $\begin{array}{l}\text { Tetitlán } \\
\text { Tecpán de Galeana }\end{array}$ & $\begin{array}{l}\text { Little y cols., 1966; Tay y } \\
\text { Biagi, 1964; Biagi y cols., } \\
\text { 1964; Tay y cols., 1969, } \\
\text { 1973; Tay, } 1969 .\end{array}$ \\
\hline JALISCO & Mezquitic & Mezquitic & Tay y Biagi, 1964. \\
\hline MICHOACAN & Venustiano Carranza* & Venustiano Carranza & $\begin{array}{l}\text { Tay y Biagi, 1964; Tay y } \\
\text { cols., } 1967 .\end{array}$ \\
\hline NAYARIT & Jala Jala & & Tay, 1969. \\
\hline OAXACA & $\begin{array}{l}\text { Tutepec } \\
\text { Collantes } \\
\text { Pinotepa Nacional } \\
\text { Rio Grande } \\
\text { Juquila } \\
\text { Lachao Nuevo } \\
\text { Cacahuatepec } \\
\text { San José de las Flores } \\
\text { Cuixtla* } \\
\text { Jamiltepec } \\
\text { Costa Chica } \\
\text { Yosondúa } \\
\text { Tlaxiaco }\end{array}$ & $\begin{array}{l}\text { Pinotepa Nacional } \\
\text { Tu tutepec } \\
\text { Juquila } \\
\text { Cacahuatepec } \\
\text { San Juan Catzocón } \\
\text { Juquila } \\
\text { Jamil tepec } \\
\text { Yosondúa } \\
\text { Tlaxiaco }\end{array}$ & $\begin{array}{l}\text { Dias, 1951; Biagi y Navarrete, } \\
\text { 1960; Tay y cols., 1961; } \\
\text { Usinger, 1944; Mazzotti y } \\
\text { Osorio, 1942; Mazzotti y Dias, } \\
\text { 1949; Tay, 1949; Tay, 1969; } \\
\text { Usinger, 1941; Biagi y cols., } \\
\text { 1960. }\end{array}$ \\
\hline
\end{tabular}

\footnotetext{
* Infección natural con T. cruzi.
} 
CUADRO No. 14

TRIATOMINOS EN MEXICO

Triatoma phyllosoma pellidipennis

(Stal, 1872)

\begin{tabular}{llll}
\hline ESTADO & LOCALIDAD REPORTADA & MUNICIPIO & REFERENCIAS \\
\hline COLIMA & Colima* & Colima & Brumpt y cols., 1939; Dias, \\
& & & $1951 ;$ Usinger, 1941; Harry y \\
& & Brumpt, 1939; Mazzotti, 1940;
\end{tabular}

\begin{tabular}{|c|c|c|c|}
\hline GUERRERO & Arcelia* & Arcelia & Brumpt y cols, 1939; Mazzotti \\
\hline & Izuala & & y Osorio, 1942; Tay y Biagi, \\
\hline & $\begin{array}{l}\text { Zumpango del Río } \\
\text { Chilpancingo }\end{array}$ & $\begin{array}{l}\text { Zumpango del Río } \\
\text { Chilpancingo }\end{array}$ & \\
\hline & $\begin{array}{l}\text { Iguala* } \\
\text { Tetela del Río* } \\
\text { Balsas }\end{array}$ & $\begin{array}{l}\text { Iguala } \\
\text { Apaxtla de Castejón }\end{array}$ & $\begin{array}{l}\text { Usinger, 1941, 1944; Mazzotti, } \\
\text { 1940; Perrin, 1949; Pérez } \\
\text { Reyes, 1953; Mazzotti, 1937; }\end{array}$ \\
\hline & Tepecoaciulo & Tepecoaciulo & Tay, 1969; Tay y cols., 1972. \\
\hline & Tlapa* & Tlapa & \\
\hline & $\begin{array}{l}\text { Sierra Madre de Guerrero } \\
\text { (Vallecito de Zaragoza y } \\
\text { los Paceres) }\end{array}$ & 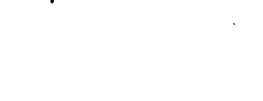 & \\
\hline & $\begin{array}{l}\text { Chilapa* } \\
\text { Acamixtla }\end{array}$ & Chilapa & \\
\hline & La Mina* & & \\
\hline & Huitzuco & Huitzuco & \\
\hline & $\begin{array}{l}\text { Rincón deł Lucero } \\
\text { Agua Zarca }\end{array}$ & Ahuacoutzingo & \\
\hline JALISCO & $\begin{array}{l}\text { Autlán* } \\
\text { Mascota* }\end{array}$ & $\begin{array}{l}\text { Autlán } \\
\text { Mascota }\end{array}$ & $\begin{array}{l}\text { Dias, 1951; Mazzotti, 1940; } \\
\text { Mazzotti y Dias, 1949; Usinger, } \\
\text { 1941. }\end{array}$ \\
\hline
\end{tabular}

\begin{tabular}{|c|c|c|c|}
\hline MEXICO & $\begin{array}{l}\text { Atencingo } \\
\text { Tutuapán* } \\
\text { Temascal tepec } \\
\text { Potrero Chico* } \\
\text { Distrito Federal }\end{array}$ & Temascal tepec & $\begin{array}{l}\text { Tay, 1969; Dias, 1951; Usinger, } \\
\text { 1941, 1944; Biagi y Navarrete, } \\
\text { 1960; Mazzotti y Dias, 1949; } \\
\text { Biagi y cols., } 1958 .\end{array}$ \\
\hline MICHOACAN & $\begin{array}{l}\text { Apatzingán * } \\
\text { Nueva I talia* } \\
\text { Carácuaro } \\
\text { Enandio } \\
\text { Jungapeo* } \\
\text { Acambaro } \\
\text { Muaracha } \\
\text { El Asoleadero* } \\
\text { Agua Blanca* } \\
\text { Parácuaro }\end{array}$ & $\begin{array}{l}\text { Apatzingán } \\
\text { Nueva I talia } \\
\text { Carácuaro } \\
\text { Jungapeo }\end{array}$ & $\begin{array}{l}\text { Usinger, 1941; Dias, 1951; } \\
\text { Mazzotti y Dias, 1949; Tay y } \\
\text { Biagi, 1963, 1964; Biagi, 1956; } \\
\text { Tay y cols., 1967; Mazzotti, } \\
\text { 1937, 1940; Brumpt y cols., } \\
\text { 1939; Dias y cols., 1947; Perrin } \\
\text { y cols., 1947; Mazzotti y } \\
\text { Osorio, 1942; Peréz Reyes, } \\
\text { 1953. }\end{array}$ \\
\hline MORELOS & $\begin{array}{l}\text { Villa de Ayala* } \\
\text { Zacatepec } \\
\text { Zapotla* } \\
\text { Axochoapan } \\
\text { Las Higueras* } \\
\text { Tetecala } \\
\text { Miacatlán } \\
\text { Zacoalpan de Amilpas* }\end{array}$ & $\begin{array}{l}\text { Zacatepec } \\
\text { Axochoapan } \\
\text { Temixco } \\
\text { Tetecala } \\
\text { Miacatlán } \\
\text { Zacoalpan de Amilpas }\end{array}$ & $\begin{array}{l}\text { Tay y cols., 1972, 1972, 1973; } \\
\text { Dias, 1951; Tay, 1969; Biagia y } \\
\text { Navarrete, 1960; Mazzotti y } \\
\text { Dias, 1949; Little y cols., 1966; } \\
\text { Tay y Biagi, 1964, 1966; } \\
\text { González Hernándes y cols., } \\
\text { 1972; Usinger, 1941, 1944; } \\
\text { Mazzotti, 1940; Pérez Reyes, } 1953\end{array}$ \\
\hline
\end{tabular}

\footnotetext{
* Infección natural con T. cruzi.
} 
CUADRO No. 14

TRIATOMINOS EN MEXICO

Triatoma phyllosoma pallidipennis

(Stal, 1872)

(cont.)

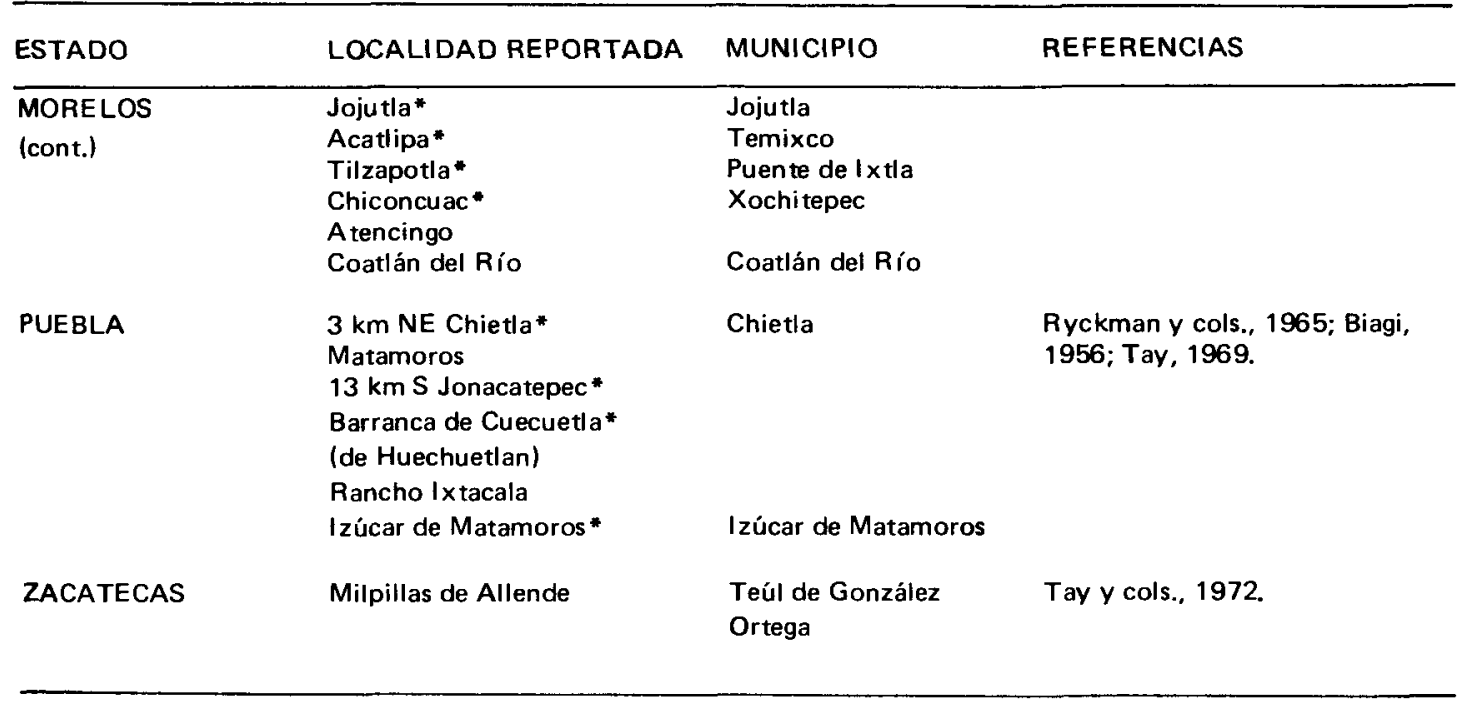

- Infección natural con $T$. cruzi.

CUADRO No. 15

TRIATOMINOS EN MEXICO

Triatoma phyllosoma picturata

(Usinger, 1939)

\begin{tabular}{|c|c|c|c|}
\hline ESTADO & LOCALIDAD REPORTADA & MUNICIPIO & REFERENCIAS \\
\hline COLIMA & No especificada. & & $\begin{array}{l}\text { Usinger, } 1941 \text {; Dias, } 1951 \text {; } \\
\text { Mazzotti y Dias, } 1949 .\end{array}$ \\
\hline JALISCO & $\begin{array}{l}\text { Autlán } \\
\text { Ixtlanhuacán del Río* }\end{array}$ & $\begin{array}{l}\text { Autlán } \\
\text { Ixtlahuacán del Río }\end{array}$ & $\begin{array}{l}\text { Mazzotti, 1940; Dias, 1951; } \\
\text { Mazzotti y Dias, 1949; Biagi y } \\
\text { Navarrete, 1960; Usinger, } \\
1941 .\end{array}$ \\
\hline NAYARIT & $\begin{array}{l}\text { Compostela* } \\
\text { Tepic } \\
\text { EI Pantanal } \\
\text { La Fortuna } \\
\text { Lo de OImedo } \\
\text { Trapiche* } \\
\text { Jalisco } \\
\text { EI Rosario* }\end{array}$ & $\begin{array}{l}\text { Compostela } \\
\text { Tepic } \\
\text { Jalisco } \\
\text { Jalisco } \\
\text { Amatlán de Caña }\end{array}$ & $\begin{array}{l}\text { Mazzotti, 1939, 1940; Usinger, } \\
\text { 1939, 1941, 1944; Dias, 1951; } \\
\text { Tay y cols., 1972; Mazzotti y } \\
\text { Osorio, 1942; Mazzotti y Dias, } \\
\text { 1949. }\end{array}$ \\
\hline OAXACA & $\begin{array}{l}\text { Chiquihuitlán * } \\
\text { Juchitán }\end{array}$ & $\begin{array}{l}\text { Chiquihuitlán } \\
\text { Juchi tán }\end{array}$ & Biagi y Navarrete, 1960. \\
\hline
\end{tabular}

- Infección natural con T. cruzi. 
CUADRO No. 16

TRIATOMINOS EN MEXICO

Triatoma phyllosoma usingeri

(Mazzotti, 1943)

\begin{tabular}{|c|c|c|c|}
\hline ESTADO & LOCALIDAD REPORTADA & MUNICIPIO & REFERENCIAS \\
\hline COLIMA & Colima & & $\begin{array}{l}\text { Usinger, 1944; Dias, 1951; } \\
\text { Mazzotti, 1943; Mazzotti y } \\
\text { Dias, 1949. }\end{array}$ \\
\hline JALISCO & $\begin{array}{l}\text { Autlán } \\
\text { Purificación }\end{array}$ & & $\begin{array}{l}\text { Mazzotti, 1943; Dias, 1951; } \\
\text { Usinger, 1944; Mazzotti y Dias, } \\
\text { 1949. }\end{array}$ \\
\hline
\end{tabular}

CUADRO No. 17

TRIATOMINOS EN MEXICO

Triatoma protracta protracta

(Uhler, 1894)

\begin{tabular}{|c|c|c|c|}
\hline ESTADO & LOCALIDAD REPORTADA & MUNICIPIO & REFERENCIAS \\
\hline BAJA CALIFORNIA & $\begin{array}{l}\text { Islas Cedros } \\
\text { Santo Tomas } \\
\text { Colonia Guerrero } \\
\text { San José } \\
3.1 \mathrm{~km} \text { S San Quintín } \\
4.3 \mathrm{~km} \text { E El Rosario }\end{array}$ & $\begin{array}{l}\text { Ensenada } \\
\text { Ensenada } \\
\text { Mexicali } \\
\text { San José }\end{array}$ & $\begin{array}{l}\text { Mazzotti y Dias, } 1949 ; \\
\text { Ryckman y Ryckman, 1961; } \\
\text { Ryckman, } 1962 .\end{array}$ \\
\hline SONORA & $\begin{array}{l}\text { N de Magdalena } \\
10 \mathrm{~km} \text { S Agua Calien te } \\
3.1 \mathrm{~km} \text { N Hermosillo } \\
\text { Cholla Valtey } \\
\text { SW de Isla Tiburón } \\
\text { Isla Tiburón }\end{array}$ & Magdalena & $\begin{array}{l}\text { Ryckman y Ryckman, 1967; } \\
\text { Ryckman, } 1962 .\end{array}$ \\
\hline
\end{tabular}

CUADRO No. 17 B

TRIATOMINOS EN MEXICO

Triatoma protracta

(subespecie inespecífica)

\begin{tabular}{llll}
\hline ESTADO & LOCALIDAD REPORTADA & MUNICIPIO & REFERENCIAS \\
\hline BAJA CALIFORNIA & Santa Cruz Tecate & Dias, 1951: Mazzotti, 1940.
\end{tabular}


CUADRO No. 18

TRIATOMINOS EN MEXICO

Triatoma protracta nahuatlae

(Ryckman, 1962)

\begin{tabular}{llll}
\hline ESTADO & LOCALIDAD REPORTADA & MUNICIPIO & REFERENCIAS \\
\hline SINALOA & $18 \mathrm{~km}$ N Los Mochis & Ahome & Ryckman, 1962; Brodie y \\
& $3.2 \mathrm{~km}$ NE EI Esquinal * & & Ryckman, 1967; Ryckman y \\
& $1.2 \mathrm{~km}$ E Mazatlán & Mazatlán & cois., 1965. \\
& $7.4 \mathrm{~km}$ N Los Mochis & Ahome & \\
\hline
\end{tabular}

- Infección natural con T. cruzi.

CUADRO No. 19

TRIATOMINOS EN MEXICO

Triatoma protracta woodi

(Usinger, 1939)

\begin{tabular}{|c|c|c|c|}
\hline ESTADO & LOCALIDAD REPORTADA & MUNICIPIO & REFERENCIAS \\
\hline CHIHUAHUA & $\begin{array}{l}139 \text { km S Juárez } \\
\text { Chihuahua } \\
49.6 \mathrm{~km} \text { S Juárez } \\
62 \mathrm{~km} \text { SE Chihuahua } \\
48 \mathrm{~km} \text { SE Chihuahua }\end{array}$ & $\begin{array}{l}\text { Juárez } \\
\text { Chihuahua } \\
\text { Juárez } \\
\text { Chihuahua } \\
\text { Chihıahua }\end{array}$ & $\begin{array}{l}\text { Ryckman, 1962; } \\
\text { Ryckman y Ryckman, } 1967 .\end{array}$ \\
\hline COAHUILA & $\begin{array}{l}\text { Sabinas* } \\
18.6 \mathrm{~km} N \text { Sabinas }\end{array}$ & $\begin{array}{l}\text { Sabinas } \\
\text { Sabinas }\end{array}$ & $\begin{array}{l}\text { Mazzotti, 1944, 1947; } \\
\text { Mazzotti y Dias, 1949; } \\
\text { Dias, 1951; Ryckman, } 1962 .\end{array}$ \\
\hline
\end{tabular}

* Infección natural con T. cruzi.

CUADRO No. 20

TRIATOMINOS EN MEXICO

Triatoma protracta zacatecensis

(Ryckman, 1962)

\begin{tabular}{llll}
\hline ESTADO & LOCALIDAD REPORTADA & MUNICIPIO & REFERENCIAS \\
\hline COAHUILA & $58.3 \mathrm{~km}$ N Saltillo & Saltillo & Ryckman, 1962. \\
DURANGO & $\begin{array}{l}240 \mathrm{~km} \mathrm{~N} \text { Durango* } \\
93 \mathrm{~km} \mathrm{~N} \text { Durango } \\
65 \mathrm{~km} \mathrm{~N} \text { Durango } \\
33.5 \mathrm{~km} \text { N Durango }\end{array}$ & $\begin{array}{l}\text { Durango } \\
\text { Durango } \\
\text { Durango } \\
\text { Durango }\end{array}$ & Ryckman y cols., 1965. \\
NUEVO LEON & $11.2 \mathrm{~km}$ S San José Raíces & & \\
SAN LUIS POTOSI & $48.4 \mathrm{~km}$ N San Luis Potosí & San Luis Potosí & Rrodie y Ryckman, 1967. \\
ZACATECAS & $54 \mathrm{~km} \mathrm{~N}$ Fresnillo & Fresnillo & Brodie y Ryckman, 1967.
\end{tabular}

* Infección natural con $T$. cruzi. 
CUADRO No. 21

TRIATOMINOS EN MEXICO

Triatoma peninsularis

(Usinger, 1940)

\begin{tabular}{|c|c|c|c|}
\hline ESTADO & LOCALIDAD REPORTADA & MUNICIPIO & REFERENCIAS \\
\hline $\begin{array}{l}\text { BAJA CALIFORNIA } \\
\text { SUR }\end{array}$ & $\begin{array}{l}3 \mathrm{~km} N \text { Cabo San Lucas } \\
1.2 \mathrm{~km} \text { N Cabo San Lucas } \\
1.2 \mathrm{~km} \text { NE Cabo San Lucas } \\
5 \mathrm{~km} \text { W Puerto Viego } \\
8 \mathrm{~km} \text { N Todos Santos } \\
3.1 \mathrm{~km} \text { N Todos Santos } \\
5.6 \mathrm{~km} \text { NE Santiago } \\
6.8 \mathrm{~km} \text { S Santa Rosalía, V. } \\
17.4 \mathrm{~km} \text { S Santo Domingo } \\
\text { La Paz } \\
38 \mathrm{~km} \text { S La Paz } \\
186 \mathrm{~km} \text { NW, } 203 \mathrm{~km} \mathrm{NW} \\
227 \mathrm{~km} \text { NW, } 240 \mathrm{NW}, \\
12.4 \mathrm{~km} \mathrm{NW,} 98 \mathrm{~km} \text { NW } \\
\text { LaPaz. }\end{array}$ & $\begin{array}{l}\text { San Juan del Cabo } \\
\text { San Juan del Cabo } \\
\text { San Juan del Cabo } \\
\text { Todos Santos } \\
\text { Todos Santos } \\
\text { Santiago } \\
\text { Santa Rosalía, Venancio } \\
\text { LaPaz } \\
\text { LaPaz } \\
\text { LaPaz }\end{array}$ & $\begin{array}{l}\text { Usinger, 1940, 1944; } \\
\text { Mazzotti y Dias, 1949; } \\
\text { Dias, 1951; Ryckman, 1962; } \\
\text { Ryckman y cols., 1965; } \\
\text { Ryckman y Ryckman, 1961, } \\
\text { 1967; Brodie y Ryckman, } 1967 .\end{array}$ \\
\hline
\end{tabular}

* Infección natural con $T$. cruzi.

CUADRO No. 22

TRIATOMINOS EN MEXICO

Triatoma recurva

(Stal, 1868)

\begin{tabular}{llll}
\hline ESTADO & LOCALIDAD REPORTADA & MUNICIPIO & REFERENCIAS \\
\hline NAYARIT & Trapiche & Mazzotti y Dias, 1949. \\
SINALOA & Santa Rosa* & & Ryckman y Ryckman, 1967; \\
& $3 \mathrm{~km}$ N Topolobampo & & Tay, 1969. \\
SONORA & $\begin{array}{l}\text { N Sonora } \\
\text { Bacabache }\end{array}$ & $\begin{array}{l}\text { San Luis Río Colorado } \\
\text { Navajoa }\end{array}$ & $\begin{array}{l}\text { Ryckman y cols., 1955; } \\
\text { Ryckman y Ryckman, 1967; } \\
\text { Tay y cols., 1972. }\end{array}$ \\
& & & \\
\hline
\end{tabular}

\footnotetext{
* Infección natural con T. cruzi.
}

\section{CUADRO No. 22 B}

TRIATOMINOS EN MEXICO

Triatoma recurva

(T. longipes, Barber, 1937)

subespecie inespecífica

\begin{tabular}{llll}
\hline ESTADO & LOCALIDAD REPORTADA & MUNICIPIO & REFERENCIAS \\
\hline NAYARIT & Trapiche & Mazzotti, 1940. \\
\hline
\end{tabular}


CUADRO No. 23

TRIATOMINOS EN MEXICO

Triatoma recurva nigricollis

(Usinger, 1944)

\begin{tabular}{llll}
\hline ESTADO & LOCALIDAD REPORTADA & MUNICIPIO & REFERENCIAS \\
\hline CHIHUAHUA & $\begin{array}{l}\text { Batopilas } \\
\text { Guazapares }\end{array}$ & $\begin{array}{l}\text { Batopilas } \\
\text { Guazapares }\end{array}$ & $\begin{array}{l}\text { Tay y Biagi, 1964; } \\
\text { Tay, 1969. }\end{array}$ \\
NAYARIT & Trapiche & & $\begin{array}{l}\text { Mazzotti y Dias, 1949; Dias, } \\
1951 ; \text { Usinger, 1944. }\end{array}$ \\
SINALOA & $\begin{array}{l}\text { Culiacán } \\
45 \mathrm{~km} N \text { Los Mochis }\end{array}$ & $\begin{array}{l}\text { Culiacán } \\
\text { Los Mochis } \\
\text { Sinaloa }\end{array}$ & $\begin{array}{l}\text { Biagi y Navarrete, 1960; } \\
\text { Ryckman y Ryckman, } 1967 .\end{array}$ \\
\hline
\end{tabular}

CUADRO No. $23 \mathrm{~B}$

TRIATOMINOS EN MEXICO

Triatoma rubida

(subespecies inespecíficas)

\begin{tabular}{|c|c|c|c|}
\hline ESTADO & LOCALIDAD REPORTADA & MUNICIPIO & REFERENCIAS \\
\hline $\begin{array}{l}\text { BAJA CALIFORNIA } \\
\text { SUR }\end{array}$ & $\begin{array}{l}\text { La Paz } \\
\text { Cabo San Lucas } \\
\text { San José del Cabo }\end{array}$ & $\begin{array}{l}\text { La Paz } \\
\text { San José del Cabo } \\
\text { San José del Cabo }\end{array}$ & $\begin{array}{l}\text { Uhler, 1894; Usinger, 1944; } \\
\text { Dias, 1951; Mazzotti, } 1940 .\end{array}$ \\
\hline GUERRERO & No especifícada. & & Perrin, 1949. \\
\hline NAYARIT & $\begin{array}{l}\text { Acaponeta } \\
\text { Santiago Ixcuintla }\end{array}$ & Acaponeta & Mazzotti, 1939, 1940, 1940. \\
\hline SINALOA & $\begin{array}{l}\text { Culiacán * } \\
\text { Tierra Blanco* } \\
\text { Imala* } \\
\text { Mocorito* } \\
\text { Navolato* } \\
\text { Magadalena }\end{array}$ & $\begin{array}{l}\text { Culiacán } \\
\text { Guamuchil } \\
\text { Culiacán } \\
\text { Mocorito } \\
\text { Culiacán }\end{array}$ & $\begin{array}{l}\text { Mazzotti, 1939, 1940; } \\
\text { Brumpt y cols., } 1939 .\end{array}$ \\
\hline
\end{tabular}

* Infección natural con T. cruzi. 
CUADRO No. 24

TRIATOMINOS EN MEXICO

Triatoma rubida rubida

(Uhler, 1894)

\begin{tabular}{|c|c|c|c|}
\hline ESTADO & LOCALIDAD REPORTADA & MUNICIPIO & REFERENCIAS \\
\hline $\begin{array}{l}\text { BAJA CALIFORNIA } \\
\text { SUR }\end{array}$ & $\begin{array}{l}\text { La Paz } \\
\text { Cabo San Lucas } \\
275 \mathrm{~km} \text { NW La Paz* } \\
5 \text { SE EI Coyote } \\
96 \mathrm{~km} \text { NW La Paz } \\
186 \mathrm{~km} \text { NW La Paz } \\
203 \mathrm{~km} \text { NW La Paz } \\
227 \mathrm{~km} \text { NW La Paz } \\
240 \mathrm{~km} \text { NW La Paz } \\
6 \mathrm{~km} \text { W Puerto Viego } \\
35 \mathrm{~km} \text { S La Paz } \\
8 \mathrm{~km} \text { N Todos Santos } \\
37 \mathrm{~km} \text { S La Paz } \\
\text { San Francisquito Bay } \\
14 \mathrm{~km} \text { NE Santiago } \\
3.1 \mathrm{~km} \text { E San lgnacio } \\
1.9 \mathrm{~km} \text { E El Coyote Bay } \\
23.6 \mathrm{~km} \text { NE Comondy } \\
230 \mathrm{~km} \text { N La Paz } \\
98 \mathrm{~km} \text { NW La Paz } \\
3.1 \mathrm{~km} \text { N Todos Santos } \\
1.2 \mathrm{~km} \text { NE Cabo San Lucas } \\
1.9 \mathrm{~km} \text { N Santiago } \\
5.6 \mathrm{~km} \text { NE Santiago }\end{array}$ & $\begin{array}{l}\text { La Paz } \\
\text { San José del Cabo } \\
\text { LaPaz } \\
\text { La Paz } \\
\text { La Paz } \\
\text { LaPaz } \\
\text { LaPaz } \\
\text { La Paz } \\
\text { La Paz } \\
\text { Todos Santos } \\
\text { La Paz } \\
\text { Santiago } \\
\text { Santa Rosalía } \\
\text { La Paz } \\
\text { La Paz } \\
\text { Todos Santos } \\
\text { San José del Cabo } \\
\text { Santiago } \\
\text { Santiago }\end{array}$ & $\begin{array}{l}\text { Usinger, 1944; } \\
\text { Ryckman y Ryckman, 1961; } \\
\text { Ryckman y Ryckman, 1967, } \\
1967 .\end{array}$ \\
\hline NAYARIT & No específicada. & & Mazzotti y Dias, 1949. \\
\hline SINALOA & 51 km NW Los Mochis* & Ahome & $\begin{array}{l}\text { Mazzotti y Dias, } 1949 ; \\
\text { Ryckman y Ryckman, } 1967 .\end{array}$ \\
\hline SONORA & $\begin{array}{l}8 \mathrm{~km} \text { N Sonora } \\
\text { Cholla Valley } \\
\text { Sausal Valley } \\
50.2 \mathrm{~km} \text { W Sonoita }\end{array}$ & $\begin{array}{l}\text { San Luis Río Colorado } \\
\text { Puerto Peñasco }\end{array}$ & $\begin{array}{l}\text { Mazzotti y Dias, 1949; } \\
\text { Ryckman y Ryckman, 1969, } \\
\text { 1967; Ryckman y Olsen, } 1960 .\end{array}$ \\
\hline
\end{tabular}

* Infección natural con T. cruzi.

CUADRO No. 25

TRIATOMINOS EN MEXICO

Triatoma rubida cochimiensis

(Ryckman, 1967)

\begin{tabular}{llll}
\hline ESTADO & LOCALIDAD REPORTADA & MUNICIPIO & REFERENCIAS \\
\hline $\begin{array}{l}\text { BAJA CALIFORNIA } \\
\text { NORTE }\end{array}$ & Norte, centro y sur & Ryckman, 1967. \\
$\begin{array}{l}\text { BAJA CALIFORNIA } \\
\text { SUR }\end{array}$ & $\begin{array}{l}240 \mathrm{~km} \text { NW La Paz } \\
\text { norte, centro y sur }\end{array}$ & La Paz & $\begin{array}{l}\text { Brodie y Ryckman, 1967; } \\
\text { Ryckman, 1967. }\end{array}$ \\
\hline
\end{tabular}


CUADRO No. 26

TRIATOMINOS EN MEXICO

Triatoma rubida jaegeri

(Ryckman, 1967)

\begin{tabular}{llll}
\hline ESTADO & LOCALIDAD REPORTADA & MUNICIPIO & REFERENCIAS \\
\hline $\begin{array}{l}\text { BAJA CALIFORNIA } \\
\text { SUR }\end{array}$ & Isla Pond & Ryckman, 1967. \\
\hline
\end{tabular}

CUADRO No. 27

TRIATOMINOS EN MEXICO

Triatoma rubida sonoriana

(Del Ponte, 1930)

\begin{tabular}{|c|c|c|c|}
\hline ESTADO & LOCALIDAD REPORTADA & MUNICIPIO & REFERENCIAS \\
\hline $\begin{array}{l}\text { BAJA CALIFORNIA } \\
\text { SUR }\end{array}$ & Isla Partida & . & Biagi, 1956. \\
\hline NAYARIT & $\begin{array}{l}\text { Santiago Ixcuintla* } \\
\text { Acaponeta } \\
\text { La Fortuna }\end{array}$ & $\begin{array}{l}\text { Santiago I xcuintla } \\
\text { Acapone ta }\end{array}$ & Usinger, 1941, 1944. \\
\hline SINALOA & $\begin{array}{l}\text { Culiacán } \\
\text { Imala } \\
\text { Mocorito } \\
\text { Navolato } \\
\text { Pozole } \\
\text { El Verde } \\
\text { Tierra Blanca } \\
24 \mathrm{~km} \mathrm{~S} \mathrm{Los} \mathrm{Mochis} \\
8 \mathrm{~km} \mathrm{E} \mathrm{Los} \mathrm{Mochis} \\
45 \mathrm{~km} \mathrm{~N} \mathrm{Los} \mathrm{Mochis} \\
19 \mathrm{~km} N \text { Los Mochis* } \\
50 \mathrm{~km} N \text { Los Mochis* } \\
\text { El Cubilete } \\
\text { Magdalena }\end{array}$ & $\begin{array}{l}\text { Culiacán } \\
\text { Culiacán } \\
\text { Mocori to } \\
\text { Culiacán } \\
\text { Mazatlán } \\
\text { Mazatlán } \\
\text { Ahome } \\
\text { Ahome } \\
\text { Ahome } \\
\text { Ahome } \\
\text { Ahome } \\
\text { Guasave } \\
\text { Guasave }\end{array}$ & $\begin{array}{l}\text { Brodie y Ryckman, 1967; } \\
\text { Dias, 1951; Tay, 1969; Mazzotti } \\
\text { y Dias, 1949; Biagi y Navarrete, } \\
\text { 1960; Tay y Biagi, 1964; } \\
\text { Usinger, 1944; Ryckman y } \\
\text { Ryckman, 1967; Ryckman y } \\
\text { cols., } 1965 .\end{array}$ \\
\hline SONORA & $\begin{array}{l}\text { Magdalena } \\
\text { Guaymas* } \\
\text { Huasabas } \\
3.1 \mathrm{~km} \mathrm{~N} \mathrm{Guaymas*} \\
3.7 \mathrm{~km} \mathrm{~N} \text { Hermosillo* } \\
96 \mathrm{~km} \mathrm{~S} \text { Guaymas* } \\
4.8 \mathrm{~km} \mathrm{~N} \mathrm{línea} \mathrm{Sinaloa-Son.*} \\
\text { Cruz de Piedra* } \\
\text { Arivechi* } \\
\text { Bacadehuachi } \\
\text { Tepache }\end{array}$ & $\begin{array}{l}\text { Magdalena } \\
\text { Guaymas } \\
\text { Huasabas } \\
\text { Guaymas } \\
\text { Hermosillo } \\
\text { Guaymas } \\
\text { Arivechi } \\
\text { Bacadehuachi } \\
\text { Tepache }\end{array}$ & $\begin{array}{l}\text { Dias, } 1951 \text {; Tay, 1969; } \\
\text { Ryckman, 1953; Little y cols., } \\
\text { 1966; Mazzotti y Dias, 1949; } \\
\text { Tay v Biagi, 1964; Palencia y } \\
\text { Julia, 1960; Ryckman y cols., } \\
1965 .\end{array}$ \\
\hline
\end{tabular}

\footnotetext{
* Infección natural con T. cruzi.
} 
CUADRO No. 28

TRIATOMINOS EN MEXICO

Triatoma rubida uhleri

(Neiva, 1911)

\begin{tabular}{llll}
\hline ESTADO & LOCALIDAD REPORTADA & MUNICIPIO & REFERENCIAS \\
\hline CHIHUAHUA & $139 \mathrm{~km}$ S Juárez & $\begin{array}{l}\text { Juárez } \\
\text { Chihuahua }\end{array}$ & Ryckman y Ryckman, 1967. \\
SONORA & $48 \mathrm{~km}$ SE Chihuahua & Imuris & \\
& Imuris & Naco & Wehrle, 1939; Mazzotti, 1940; \\
& Naco & Huasabas & Dias, 1951; Tay y Biagi, 1964; \\
& Huasabas & Guaymas & y Julia, 1960; Ryckman y \\
& Guaymas & Puerto Peñazco & Ryckman, 1967; Ryckman y \\
& $130 \mathrm{~km}$ W Sonoita & Magdalena & cols., 1965. \\
& N Magdalena & Hermosillo & \\
& N Hermosillo & & \\
& $10 \mathrm{~km}$ S Agua Caliente & & \\
& $29 \mathrm{~km}$ SE Caborca* & Puerto Peñazco & \\
$27 \mathrm{~km}$ W Sonoita & Hermosillo & \\
& $56 \mathrm{~km}$ N Hermosillo* & & \\
& & &
\end{tabular}

- Infección natural con T. cruzi.

CUADRO NO. 28 B

TRIATOMINOS EN MEXICO

Triatoma rubida entre sonoriana $y$ uhleri

\begin{tabular}{|c|c|c|c|}
\hline ESTADO & LOCALIDAD REPORTADA & MUNICIPIO & REFERENCIAS \\
\hline $\begin{array}{l}\text { BAJA CALIFORNIA } \\
\text { SUR }\end{array}$ & $\begin{array}{l}264 \mathrm{~km} \mathrm{~N} \mathrm{La} \mathrm{Paz*} \\
4.8 \mathrm{~km} \mathrm{~S} \text { El Coyote Bay* }\end{array}$ & $\mathrm{LaPaz}$ & $\begin{array}{l}\text { Ryckman y cols., } 1965 ; \\
\text { Ryckman y Ryckman, } 1967 .\end{array}$ \\
\hline SONORA & Sur de Guaymas* & Guaymas & $\begin{array}{l}\text { Ryckman y cols., 1965; } \\
\text { Ryckman y Ryckman, } 1976 .\end{array}$ \\
\hline
\end{tabular}

* Infección natural con T. cruzi.

CUADRO No. 29

TRIATOMINOS EN MEXICO

Triatoma sanguisuga sanguisuga

(Le Conte, 1855)

\begin{tabular}{|c|c|c|c|}
\hline ESTADO & LOCALIDAD REPORTADA & MUNICIPIO & REFERENCIAS \\
\hline MEXICO & México & & $\begin{array}{l}\text { Mazzotti y Dias, 1949; } \\
\text { Usinger, 1939, 1944; } \\
\text { Dias, 1951. }\end{array}$ \\
\hline
\end{tabular}


CUADRO No. 30

TRIATOMINOS EN MEXICO

Triatoma sanguisuga indictiva

(Neiva, 1912)

\begin{tabular}{llll}
\hline ESTADO & LOCALIDAD REPORTADA & MUNICIPIO & REFERENCIAS \\
\hline CHIHUAHUA & Ciudad Juárez & Ciudad Juárez & Dias, 1951; Usinger, 1944. \\
\hline
\end{tabular}

CUADRO No. 31

TRIATOMINOS EN MEXICO

Triatoma snaguisuga occidentalis

(Usinger, 1944)

\begin{tabular}{llll}
\hline ESTADO & LOCALIDAD REPORTADA & MUNICIPIO & REFERENCIAS \\
\hline SINALOA & $\begin{array}{l}\text { Costa Oeste } \\
\text { Mazatlán }\end{array}$ & Mazatlán & $\begin{array}{l}\text { Dias, 1951; Usinger, 1944; } \\
\text { Mazzotti y Dias, 1949. }\end{array}$ \\
\hline
\end{tabular}

CUADRO No. 32

TRIATOMINOS EN MEXICO

Triatoma sinaloensis

(Ryckman, 1962)

\begin{tabular}{|c|c|c|c|}
\hline ESTADO & LOCALIDAD REPORTADA & MUNICIPIO & REFERENCIAS \\
\hline SINALOA & $\begin{array}{l}6.8 \mathrm{~km} \text { E El Fuerte } \\
45 \mathrm{~km} N \text { Los Mochis } \\
50 \mathrm{~km} \mathrm{~N} \mathrm{Los} \mathrm{Mochis*}\end{array}$ & $\begin{array}{l}\text { El Fuerte } \\
\text { Ahoma } \\
\text { Ahoma }\end{array}$ & $\begin{array}{l}\text { Ryckman y cols., 1965; } \\
\text { Ryckman, 1962; } \\
\text { Boodie y Ryckman, 1967; } \\
\text { Ryckman y Ryckman, } 1967 .\end{array}$ \\
\hline SONORA & $\begin{array}{l}6.8 \text { km N Navajoa } \\
8 \text { km N Guaymas } \\
\text { Guaymas* } \\
\text { S de Guaymas } \\
58 \text { km S Guaymas* } \\
96 \text { km S Guaymas* }\end{array}$ & $\begin{array}{l}\text { Navojoa } \\
\text { Guaymas } \\
\text { Guaymas } \\
\text { Guaymas }\end{array}$ & $\begin{array}{l}\text { Ryckman, 1962; Ryckman y } \\
\text { Ryckman, 1967, } 1967 .\end{array}$ \\
\hline
\end{tabular}

* Infección natural con T. cruzi. 
CUADRO No. 30

TRIATOMINOS EN MEXICO

Triatoma sanguisuga indictiva

(Neiva, 1912)

\begin{tabular}{llll}
\hline ESTADO & LOCALIDAD REPORTADA & MUNICIPIO & REFERENCIAS \\
\hline CHIHUAHUA & Ciudad Juárez & Ciudad Juárez & Dias, 1951; Usinger, 1944. \\
\hline
\end{tabular}

CUADRO No. 31

TRIATOMINOS EN MEXICO

Triatoma snaguisuga occidentalis

(Usinger, 1944)

\begin{tabular}{llll}
\hline ESTADO & LOCALIDAD REPORTADA & MUNICIPIO & REFERENCIAS \\
\hline SINALOA & $\begin{array}{l}\text { Costa Oeste } \\
\text { Mazatlán }\end{array}$ & Mazatlán & $\begin{array}{l}\text { Dias, 1951; Usinger, 1944; } \\
\text { Mazzotti y Dias, 1949. }\end{array}$ \\
\hline
\end{tabular}

CUADRO No. 32

TRIATOMINOS EN MEXICO

Triatoma sinaloensis

(Ryckman, 1962)

\begin{tabular}{|c|c|c|c|}
\hline ESTADO & LOCALIDAD REPORTADA & MUNICIPIO & REFERENCIAS \\
\hline SINALOA & $\begin{array}{l}6.8 \mathrm{~km} \text { E El Fuerte } \\
45 \mathrm{~km} \mathrm{~N} \mathrm{Los} \mathrm{Mochis} \\
50 \mathrm{~km} \mathrm{~N} \mathrm{Los} \mathrm{Mochis*}\end{array}$ & $\begin{array}{l}\text { El Fuerte } \\
\text { Ahoma } \\
\text { Ahoma }\end{array}$ & $\begin{array}{l}\text { Ryckman y cols., 1965; } \\
\text { Ryckman, 1962; } \\
\text { Boodie y Ryckman, 1967; } \\
\text { Ryckman y Ryckman, 1967. }\end{array}$ \\
\hline SONORA & $\begin{array}{l}6.8 \mathrm{~km} \text { N Navajoa } \\
8 \mathrm{~km} \mathrm{~N} \text { Guaymas } \\
\text { Guaymas* } \\
\text { S de Guaymas } \\
58 \mathrm{~km} \mathrm{~S} \text { Guaymas* } \\
96 \mathrm{~km} \mathrm{~S} \text { Guaymas* }\end{array}$ & $\begin{array}{l}\text { Navojoa } \\
\text { Guaymas } \\
\text { Guaymas } \\
\text { Guaymas }\end{array}$ & $\begin{array}{l}\text { Ryckman, 1962; Ryckman y } \\
\text { Ryckman, 1967, } 1967 .\end{array}$ \\
\hline
\end{tabular}

* Infección natural con T. cruzi. 


\section{CUADRO No. 33}

TRIATOMINOS EN MEXICO

Dipetalogaster maximus

(Uhler, 1894)

\begin{tabular}{|c|c|c|c|}
\hline ESTADO & LOCALIDAD REPORTADA & MUNICIPIO & REFERENCIAS \\
\hline $\begin{array}{l}\text { BAJA CALIFORNIA } \\
\text { SUR }\end{array}$ & $\begin{array}{l}\text { La Paz* } \\
\text { San José del Cabo } \\
\text { Cabo San Lucas } \\
\text { Canón del Cajoncito y } \\
\text { vinoramos } \\
35 \mathrm{~km} \text { S La Paz } \\
10 \mathrm{~km} \mathrm{SW} \mathrm{La} \mathrm{Paz} \\
20 \mathrm{~km} \text { E La Paz } \\
3 \mathrm{~km} \text { N Cabo San Lucas } \\
\text { EI Triunfo }\end{array}$ & $\begin{array}{l}\text { La Paz } \\
\text { San José del Cabo } \\
\text { San José del Cabo } \\
\text { La Paz } \\
\text { La Paz } \\
\text { La Paz } \\
\text { San José del Cabo } \\
\text { El Triunfo }\end{array}$ & $\begin{array}{l}\text { Uhler, 1894; Dias, 1951; } \\
\text { Usinger, 1939, 1944; } \\
\text { Ryckman y cols., 1965; } \\
\text { Ryckman y Ryckman, 1961, } \\
\text { 1967; Larrousse, 1924; } \\
\text { Mazzotti, 1940, 1940; Mazzotti } \\
\text { y Dias, 1949; Brodie y } \\
\text { Ryckman, 1967. }\end{array}$ \\
\hline
\end{tabular}

- Infección natural con T. cruzi.

CUADRO No. 34

TRIATOMINOS EN MEXICO

Eratyrus cuspidatus

(Stal, 1859)

\begin{tabular}{llll}
\hline ESTADO & LOCALIDAD REPORTADA & MUNICIPIO & REFERENCIAS \\
\hline VERACRUZ & Catemaco & Catemaco & $\begin{array}{l}\text { Comunicación personal Dr. } \\
\text { Dionisio Peláez, junio 1977. }\end{array}$ \\
\hline
\end{tabular}

CUADRO No. 35

TRIATOMINOS EN MEXICO

Panstrongr/us geniculatus

(Latreille, 1811)

\begin{tabular}{llll}
\hline ESTADO & LOCALIDAD REPORTADA & MUNICIPIO & REFERENCIAS \\
\hline VERACRUZ & Catemaco & Catemaco & $\begin{array}{l}\text { Comunicación personal Dr. } \\
\text { Dionisio Peláez, junio 1977. }\end{array}$ \\
\end{tabular}

CUADRO No. 36

TRIATOMINOS EN MEXICO

Paratriatoma hirsuta kamiensis

(Ryckman, 1967)

\begin{tabular}{llll}
\hline ESTADO & LOCALIDAD REPORTADA & MUNICIPIO & REFERENCIAS \\
\hline $\begin{array}{l}\text { BAJA CALIFORNIA } \\
\text { NORTE }\end{array}$ & Laderas de San Pedro Martir & Ryckman, 1971, 1967.
\end{tabular}


CUADRO No. 37

TRIATOMINOS EN MEXICO

Paratriatoma hirsuta papagoensis

(Ryckman, 1967)

\begin{tabular}{llll}
\hline ESTADO & LOCALIDAD REPORTADA & MUNICIPIO & REFERENCIAS \\
\hline SONORA & N Desierto & & Ryckman y OIsen, 1960; \\
& $135 \mathrm{~km}$ W Sonoita & Puerto Peñazco & Ryckman, 1971, 1967; \\
& $50.2 \mathrm{~km}$ W Sonoita & Puerto Peñazco & Ryckman y Ryckman, 1967. \\
\hline
\end{tabular}

CUADRO No. 38

TRIATOMINOS EN MEXICO

Paratriatoma hirsuta yumanensis

(Ryckman, 1967)

\begin{tabular}{llll}
\hline ESTADO & LOCALIDAD REPORTADA & MUNICIPIO & REFERENCIAS \\
\hline BAJA CALIFORNIA & Bahia San Francisquito & Ensenada & Brodie y Ryckman, 1967; \\
NORTE & Arroyo de Calamgue & Ensenada & Ryckman, 1971, 1967; \\
& 5 km E Las Arras tras & & Ryckman y Ryckman, 1961, \\
& San Agustín & Ensenada & 1967. \\
& San lgnacio & Ensenada & \\
& Bahia de los Angeles & Ensenada & \\
\hline
\end{tabular}

CUADRO No. 39

TRIATOMINOS EN MEXICO

Rhodnius prolix us

(Stal, 1859)

\begin{tabular}{|c|c|c|c|}
\hline ESTADO & LOCALIDAD REPORTADA & MUNICIPIO & REFERENCIAS \\
\hline \multirow[t]{3}{*}{ CHIAPAS } & $\begin{array}{l}\text { Villa de Chilón } \\
\text { León Brindis* }\end{array}$ & Villa de Chilón & $\begin{array}{l}\text { Tay, 1969; Dias, 1951; } \\
\text { Mazzotti y Dias, 1949; }\end{array}$ \\
\hline & Agua Azul Chiquito* & Chilón & Tay y Biagi, 1964; \\
\hline & Ococingo & Ococingo & Ortega Gutiérrez y cols. 1976. \\
\hline \multirow[t]{4}{*}{ OAXACA } & $\begin{array}{l}\text { Teojomulco* (Mina del } \\
\text { Carmen) }\end{array}$ & & $\begin{array}{l}\text { Mazzotti, 1938, 1940; } \\
\text { Brumpt y cols., 1939; }\end{array}$ \\
\hline & $\begin{array}{l}\text { San José de las Flores* } \\
\text { Jamil tepec* }\end{array}$ & $\begin{array}{l}\text { Cotozocán } \\
\text { Jamil tepec }\end{array}$ & $\begin{array}{l}\text { Dias, 1951; Biagi y Navarrete, } \\
\text { 1960; Mazzotti y Dias, 1949; }\end{array}$ \\
\hline & $\begin{array}{l}\text { Putla* } \\
\text { Cerro del Aire (cerca de } \\
\text { Nopala) }\end{array}$ & Putla & $\begin{array}{l}\text { Usinger, 1944; Tay y cols., } \\
1961 \text {; Goldsmith y cols., } 1977 .\end{array}$ \\
\hline & $\begin{array}{l}\text { Región en tre Oaxaca y } \\
\text { Guerrero. }\end{array}$ & & Biagi y cols., 1960. \\
\hline
\end{tabular}

\footnotetext{
* Infección natural con T. cruzi.
} 


\section{RESUMO:}

É a apresentação dos dados obtidos a partir de uma minuciosa revisão feita na literatura médica mexicana e estrangeira com relação à doença de Chagas no México. O estudo refere-se ao periodo de 1939 quando, pela primeira vez, menciona-se Trypanosoma cruzi no México, até 1976.

Através de mapas, tabelas e quadros são mostrados os lugares onde foram encontrados casos humanos, reservatórios e transmissores. São feitos comentários sobre os resultados obtidos e é ressaltada a necessidade de ampliação dos estudos sobre a doença de Chagas no México.

\section{SUMMARY}

A thorough review of the literature is made regarding Chagas disease in Mexico and e/sewhere since 1939, when Trypanosoma cruzi was first reported in this country until 1976.

The location where human cases, non human reservoirs and transmitters have been found is pointed out by means of maps, tables and charts comments are made regarding the results reported. The importance of increasing the studies of Chagas' disease in our country is stressed.

\section{REFERENNCIAS BIBLIOGRAFICAS}

1. ACEVES, S.: Un caso probable de miocarditis chagásica; primer caso presentado en México. Sesión ordinaria Acad. Nal. Med. 1950. Comunicación personal. Dic. 1964.

2. AGUIRRE-PEQUEÑO, E.: Una nueva localidad en la distribución geográfica de las triatomas naturalmente infectadas por Trypanosoma cruzi en la República Mexicana. Arch. Med. Mex. 5(8) : 350-358, 1947.

3. AGUIRRE-PEQUEÑO, E.: Presencia de Trypanosoma cruzi en mamíferos $V$ triatomideos de Nuevo León, Monterrey. Arch. Med. Mex. 5(8) : 359-363, 1956.

4. AJA, E.: Influencia de la humedad y la temperatura sobre la virulencia de una cepa de T. cruzi. Tesis. Esc. Nal. Cienc. Biol. I. P.N. 1955.
5. BERNAL-FLANDES, F.: Anotaciones sobre triatomas $y$ tripanosoma s. Rev. Med. Veracruzana. 18(5): 10, 1938.

6. BELTRÁN, E.: Hallazgo de Schyzotrypanum cruzi en un ratón Rattus norvegicus de la ciudad de México. Rev. Soc. Mex. Hist. Nat. 10(1-4): 15, 1949.

7. B|AGI-F., F.: Nueva infección natural por Scizotrypanum cruzi. Variabilidad cromática $\mathrm{y}$ otras notas sobre triatomas mexicanas. Prensa Méd. Mexicana. $21(7-10):$ 123-126, 1956.

8. BIAGI-F.; F.; GUZMÁN-GARCIA， C.; NAVARRETE, F.; TAY, J.; PORTILHA, J. Y OLIVARES S. : Enfermedad de Chagas en Tutuapan, estado de México. Prensa Méd. Mexicana, 23 (11-12): 463-465, 1958.

9. BIAGI-F.; F.; PÉREZ, T.R.; GOYCOLEA, O. Y TAY, J.: Estado actual de nuestro conocimientos sobre la enfermedad de Chagas en México. Il. Infección en vertebrados. An. Cong. Internac. Doença Chagas (Rio de Janeiro, 1959), $1: 383-402,1960$.

10. BIAGI-F., F. Y NAVARRETE, F.: Estado actual de nuestros conocimientos sobre la enfermedad de Chagas en México. I. Transmisores. An. Cong. Internac. Doença Chagas (Rio de Janeiro, 1959) , 1: 285-295, 1961.

11. BIAGI-F., F.; TAY, J.; GUZMÁN-F., C. $Y$ FONG, F.F.: Tetitlán, Guerrero foco endémico de enfermedad de Chagas. Rev. Fac. Med. México, 6(9): 625-631, 1964.

12. BIAGI-F., F. Y ARCE, G.E.: Los dos primeros casos de miocarditis chagásica comprobados en México. Arch Inst. Cardiol. México, 35(5):611-623, 1965.

13. BIAGI-F., F.; TAY, J. AND GUTIÉRREZ, Q.M.: Behavior of different Mexican strains of Trypanosoma cruzi in the withe mouse. Progress in Protozoology exerta Med. Amsterdan pp. 142, 1965.

14. BRUMPT, E.; MAZZOTI, L. Y BRUMPT, 
L.C.: Enquetes épidémiologiques sur la maladie de $C$. Chagas au Mexique (1). Réduvidés vecteurs. Animaux réservoirs de virus. Cas humanins. Ann. Parasitol., 17(4) : 299-312, 1939.

15. CUARTERO, C.M.; PONCE, E.C. Y RECIO, R.: Cinco nuevos casos de enfermedad de Chagas en Zacatecas $y$ Jalisco, República Mexicana. Rev. Invest. Salud Públ., México, 27(1): 29-36, 1967.

16. DIAS, E.: Doença de Chagas nas Américas II. México. (Chagas Disease in the Américas. II. México). Rev. Brasil. Malariol. 3(4) : 555-570, 1951.

17. Encuestas serológicas múltiples y bancos de la OMS para sueros de referencias. Informe de um grupo científico de la OMS. Serie Inf. Técn. 474 OM: Ginebra 1970.

18. GARCIA, W. Y MUHLPFORDT, H.: Infección de Trypanosoma cruzi en ratones después de su tratamiento con Trypanosoma lewisi. Rev. Inst. Med. Trop. S. Paulo. 11(1): 13-18, 1969.

19. GOLDSMITH, R.S.; KAGAN, I.G., REYES-GONZÁLEZ, M.A. Y CEDEÑO FERREIRA, J.: Estudios seroepidemiológicos realizados en Oaxaca, Mé. xico. 1. Encuesta de anticuerpos parasitarios mediante la prueba de hemaglutinación indirecta. Bol. Ofna. Sanit. Panamer. 69(6) : 500-517, 1971.

20. GONZÁLEZ-ANGULO, W. AND RYCKMAN, R.E.: Epizootiology of Trypanosoma cruzi in sout western North America. IX. An investigation to determine the incidence of Trypanosoma cruzi infections in Triatominae and man on the Yucatan Peninsula in México. J. Med. Entom. 4: 44-47, 1967.

21. GONZÁLEX, A.; SERAFIN, F.F. Y RESAN, F.: Un nuevo caso de enfermedad de Chagas em México. Gac. Med. Mex. 103(2): 167, 1972.

22. HERNÁNDEZ, J.: Un nuevo caso de enfermedad de Chagas en Tierra Blanca, Ve- racruz. Rev. Inst. Salub. Enferm. Trops. (Méx.) 25(2) : 181, 1965.

23. LARANJA, F.; DIOS, E.; NOBREGA, G.: $O$ electrocardiograma na cardiopatia cronica da Doença de Chagas. Mem. 2. Congr. Interamer. Cardiol. México 3: 1476-1477, 1948.

24. LENT, H.: Triatonia longipes barber, 1937; un sinónimo de Triatoma recurva (Stal 1968). Ciencia (México, D.F.) $11(5-6)$ : 156-158, 1961.

25. LITTLE, J.W.; TAY, J. Y BIAGI-F., F.: A study on the susceptibility of triatomid bugs to some Mexican strains of Trypasoma cruzi. J. Med. Entom. 3(3-4) : 252-255, 1966.

26. MARTINEZ, R.; CALDERA, M. Y RIO, A. del: Estudio sobre tripanosomiasis en Zacatecas. I. Un nuevo caso, típico de enfermedad de Chagas aguda, en Tepechitlán. Rev. Invest. Sal. Públ. (Méx.). 32(2): 130, 1972.

27. MAZZOTTI, L.: Investigación sobre la existancia de la enfermedad de Chagas en el País. Demostración de tripanosomas en los reduvideos transmisores. Medicina, México (282), 16: 584-585, 1936.

28. MAZZOTTI, L.: Infeción natural de Trypanosoma cruzi de Chagas en Triatoma phyllosoma Burmmeister y Triatoma pallidipennis de la Costa del Pacífico Medicina, México (289), 17: 161-166, 1937.

29. MAZZOTTI, L. : Infección natural por Trypanosoma cruzi en otras dos especies de triatomas. Rev. Inst. Salub. Enferm. Trop., México, 1(1): 73-78, 1939.

30. MAZZOTTI, L.: Triatomideos de México y su infección natural por Trypanosoma cruzi Chagas. Medicina, México (358), 20: 95-109, 1940.

31. MAZZOTTI, L.: Variations in virulence for mice and guinea pigs in strains of Trypanosoma cruzi Chagas from different species of bugs (Triatomidade) 
from different localities in México. Am. J. Hyg. 31 (3) : 67-85, 1940.

32. MAZZOTTI, L.: Resultados obtenidos por la inoculación de ratones con pequenas $y$ grandes cantidades de Trypanosoma cruzi. Rev. Inst. Salub. Enferm. Trop., México. 1(2): 181-187, 1940.

33. MAZZOTTI, L.: Dos casos de enfermedad de Chagas en el estado de Oaxaca. Gac. Med. México, 70(4): 417-420, 1940.

34. MAZZOTTI, L. Y DIAS, E.: Resumen de los datos publicados sobre enfermedad de Chagas en México. Rev. Soc. Hist. Nat. 10 (1-4): 103-111, 1949.

35. Memorias del 11 Congresso Mexicano de Medicina. 555-556, 1948.

36. ORTEGA, M. Y TAY, J.: Ensayo de diversas vias de infección por Trypanosoma cruzi en el ratón blanco. Bol. Chileno Parasitol. (27): 6-11, 1972.

37. ORTEGA, M.; BELTRÁN-H., F.; ZAVALA-J., J.: Enfermedad de Chagas en Chiapas. Estudios clínicos epidemiológicos. Rev. Sal. Públ. Méx. 28(5): 837-843, 1976.

38. PALENCIA, L. Y MONTAÑO. E.: Un nuevo caso de tripanosomiasis en México. Rev. Fac. Med., México, 1(11): 737-740, 1959.

39. PALENCIA, L. Y JULIÁ, J.: Triatomas transmisores de tripanosomiasis en Guaymas. Rev. Fac. Med., México, 2(7): 493-497, 1960.

40. PALOMO, E.E.: Consideraciones sobre Triatoma dimidiata (Lat.) del estado de Yucatán y su infección con Trypannosoma cruzi. Medicina; Rev. Mex. (361), 20: 175-177, 1940.

41. PALOMO, E.: Comentarios al trabajo de los doctores Emmanuel Díaz, Francisco N. Laranja y Genard Nóbrega, sobr "Clínica $y$ terapéutica de la enfermedad de Chagas". Mem. 2. Cong. Mexicano Med. (México, 1947), pp. 555-556, 1948.
42. PELÁEZ, D.: Algumas notas sobre el hallazgo en México de un microhimenóptero parásito de huevos de Triatoma pallidipennis (Stal). Ciencia, México. 5 (1-3): 29-33, 1944.

43. PELÃEZ, D.: Comunicación per sonal sobre Eratyrus Panstrongylus.

44. PÉREZ-REYES, R.: Diferenciación serologica de algunas especies de la familia Trypanosomidae. Rev. Palud. y Med. Trop., México. 2(1): 1-22, 1950.

45. PÉREZ-REYES, R.: El origen de los tripanosomas en cultivos de Schizotrypa. num cruzi. Rev. Inst. Salub. y Enferm. Trop., México, 13(2): 101-109, 1950.

46. PÉREZ-REYES, R.: Efecto de la pentaquina en el consumo de oxígeno de cultivos de Schizotrypanum cruzi. Ciencia, México. 12(1-2): 33-35, 1952.

47. PÉREZ-REYES, R.: Estudios sobre hematozoarios. V. La posición sistemática de Trypanosoma cruzi y sus relaciones con $T$. lewisi. Ciencia, México. 14(4-6) : 91-92, 1954.

48. PÉREZ-REYS, R.: La evolución de Schizotrypanum cruzi en ratones blancos. Ciencia, Méx. 13(9-10): 218-225, 1954.

49. PERRIN, M.: Anotaciones sobre la enfermedad de Chagas en el estado de Guerrero. Medicina, México. 592 (29): 443-444, 1949.

50. PERRINN, M.: Cardiopatía chagásica experimental con un esquistotripanosoma aislado en México (Schizotrypanum cruzi var mexicanum.) México 621 (31): 46-52, 1951.

51. PERRINN, T.G.; DIÁS, E. AND BRENES $M$. : Nota previa sobre as primeiras comprovações sorologicas da doença de Chagas no México. Mem. Inst. Oswaldo Cruz, 45(2): 395-400, 1947.

52. PINTO, C.F.: Tripanosomiasis cruzi (doença de Carlos Chagas) no Rio Grande do Sul, Brazil. Mem. Inst. Oswaldo Cruz, $37(4)$ : 443-537, 1942. 
53. QUINTAL, R.E.: ZAVALA, J. Y RODRIGUEZ, M.: La enfermedad de Chagas en el estado de Yucatán, México. Rev. Invest. Clín. (Méx.). 27: 255-258, 1975.

54. RODRIGUEZ, J.: Un nuevo caso de enfermedad de Chagas en México. Med. (Méx.). 40 (847): 291-292, 1960.

55. RYCKMAN, R.E.: Triatoma rubida sonoriana infected with Trypanosoma cruzi in Sonora, México. Pan - Pacific Entomologist. 29(3): 143-144, 1953.

56. RYCKMAN, R.E. AND RYCKMAN, A.E.: Quail nesting inside woodrat houses in Baja California. Condor. 62(6): 479-480, 1960.

57. RYCKMAN, R.E. AND RYCKMAN, A.E.: Loma Linda University's 1962 expedition to Baja California. Medical Entomology and Parasitology. Med. Arts. Sci. 17(3) : 65-76, 1963.

58. RYCKMAN, R.E.; FOLKES, L.D.; OLSEN, E.L.; ROBB, L.P. AND RCYKMAN, A.E.; Epizootiology of Trypanosoma cruzi in southwestern North America. J. Med. Entom. 2(2): 87-108, 1965.

59. RYCKMAN, R.E.; CHRISTIANSON, C.P. AND SPENCER, D.: Triatoma recurva colected from its natural host in Sonoram Mexico. J. Economic. Ent. 3: 330-332, 1965.

60. RYCKMAN, R.E. AND RYCKMAN, A.E.: Epizootiology of Trypanosoma cruzi in southwestern North America X. T e biosystematics of Dipetalogaster maximus in Mexico. (Hemiptera: Reduvidae) (Kinetoplastida: Trypanosomidae). J. Med. Entom., 4(2): 180-188, 1967.

61. RYCKMAN, R.E.: Six new populations of triatominae from western north America. Bull. Pan. Amer. Res. Inst. 1(1): $1 \cdot 3,1967$.

62. SCHETTINO, P.M.; NAVARRETE, F.; TAY, J. Y RAMOS, S.: Estudio de una cepa de Trypanosoma cruzi mexicana de virulencia. Rev. Invest. Sal. Públ. (Méx.). 35: 37-45, 1975.
63. TAY, J.; GOYCOLEA, O. Y BIAGI - F.; $F .:$ Observaciones sobre enfermedad de Chagas en la Mixteca Baja. Nuevo caso humano de la República Mexicana. Bol. Ofna. Sanit. Panamer. 51 (4): 322-327, 1961.

64. TAY, J.; NAVARRETE, C.E.; CORAMINAS, E.R. Y BIAGI-F., F.: La enfermedad de Chagas en el municipio de Tuxpan, estado de Michoacán. México. Rev. Fac. Med. (Méx.) 8(4) : 270, 1966.

65. TAY, J.; BIAGI-F., F. Y DE BUEN, A.M.: Estado actual de conocimientos sobre triatomas del estado de Morelos, México. Rev. Fac. Med. Méx. 8(7): 451-461, 1966.

66. TAY, J.; Descripción de Leishmaniasis mexicana mediante el microscopio electrónico. Prensa Méd. Mex. 31(9-10): 295-305, 1966.

67. TAY, J.; BIAGI-F., F. Y DE BUEN, A.M.: Estado actual de conocimientos sobre triatomas $y$ enfermedad de Chagas en Michoacán. México. Rev. Fac. Med. Mex. 9(2): 109-121, 1967.

68. TAY, J.; BIAGI-F., F. Y DE BUEN, A.M.: Estado actual de conocimientos sobre la enfermedad de Chagas en el estado de Zacatecas. Medicina. (Méx.) 48 (1032): 121-129, 1968.

69. TAY, J.: Localidades nuevas de triatomideos mexicanas y su infección natural por Trypanosoma cruzi. Medicina (Méx.). 49 (1052): 35-43: 1969.

70. TAY, J.;SALAZAR., P.M. Y ONTIVEROS, D.: El comportamiento en el ratón blanco de una cepa de Trypanosoma cruzi mediante pases sucessivos en diferentes especies de triatomas. Rev. Lat-amer. Microbiol. (11): 79-89, 1969.

71. TAY, J.; ONTIVEROS, D.; ORTEGA, M. $Y$ TORRES, J.: Estado actual de los conocimientos sobre infección en vertebrados por la enfermedad de Chagas en la República Mexicana. Bol. Ofna. Sanit. Panamer. $67(4)$ : 310-314, 1969. 
72. TAY, J.; ORTEGA, M. Y CAPIN, R.: Enfermedad de Chagas en México. Reporte de nuevas localidades infectadas. Rev. Fac. Med. Mex. 25(3): 221-226, 1972.

73. TAY, J.; GUTIÉRREZ, M. ; SALAZAR, P.M.; CASTILLO, M. Y ORTEGA, M.: Estudios sobre seis cepas mexicanas de Trypanosoma cruzi. Rev. Invest. Sal. Públ. Méx. 33: 67-76, 1973.

74. TAY, J.;ABITI, T. Y RIVERO, A.: Acción de sueros hiperinmunes en contra de Trypanosoma cruzi. Rev. Sal. Públ. Mex. 34: 13-29, 1974.

75. TELLAECHE, L.A.: Boletín informativo de la Dirección General de Investigación. Salud Pública. Abril 1976.

76. USINGER, L.R.; The triatominae of north and central America and their public health significanse. Public. Health Bulletin No. 288, Federal Security Agency U.S. 1944.

77. VELASCO-C., O.; TAY J. Y LUNA-VALADEZ, A.: La enfermedad de Chagas en el estado de Jalisco: República Mexica- na. Presentación de 3 nuevos casos humanos. Rev. Invest. Sal. Públ. (Méx.). 34: 107-113, 1966.

78. VELASCO-C., O.; ROMERO, F. Y MENDIOLA, J.: Contribución al conocimiento de la enfermedad de Chagas en México. I. Epidemiologia de la enfermedad de Chagas en Tepechitlán, Zac. Rev. Invest. Sal. Públ. Méx. $30(3): 197-204,1970$

79. VELASCO-C., O. Y GARCIA, J.L.: Estudio clínico $y$ epidemiológico de un nuevo caso de enfermedad de Chagas en el estado de Jalisco, México. Pren. sa Méd. Mex. 35: 438-440, 1970.

80. ZAVALA, J.; ARJONA, D.; QUINTAL, R.: Enfermedad de Chagas reporte de un caso clínico. Rev. Invest. Clín. (Méx.). 25(4): 367, 1973.

81. ZAVALA, J.; QUINTAL, R.; RODRIGUEZ, M.: Enfermedad de Chagas en Yucatán. Estudio de transmisores. Reporte preliminar. Higiene. 25(3): 202-206, 1974.

82. ZAVALA, J.: Comunicación personal sobre casos humanos de enfermedad de Chagas en el estado de Yucatán. 